\title{
DNA damage and repair in plants - from models to crops
}

\author{
Vasilissa Manova ${ }^{1}$ and Damian Gruszka ${ }^{2 *}$ \\ ${ }^{1}$ Department of Molecular Genetics, Institute of Plant Physiology and Genetics, Bulgarian Academy of Sciences, Sofia, \\ Bulgaria, ${ }^{2}$ Department of Genetics, Faculty of Biology and Environment Protection, University of Silesia, Katowice, Poland
}

\section{OPEN ACCESS}

Edited by: Jan Dvorak,

University of California, USA

Reviewed by:

Barbara Hohn,

Friedrich Miescher Institute for Biomedical Research, Switzerland Kevin Culligan,

University of New Hampshire, USA

*Correspondence:

Damian Gruszka damian.gruszka@us.edu.pl

Specialty section:

This article was submitted to Plant Genetics and Genomics, a section of the journal

Frontiers in Plant Science

Received: 09 August 2015 Accepted: 05 October 2015 Published: 23 October 2015

Citation:

Manova V and Gruszka D (2015) DNA damage and repair in plants -

from models to crops.

Front. Plant Sci. 6:885.

doi: 10.3389/fp/s.2015.00885
The genomic integrity of every organism is constantly challenged by endogenous and exogenous DNA-damaging factors. Mutagenic agents cause reduced stability of plant genome and have a deleterious effect on development, and in the case of crop species lead to yield reduction. It is crucial for all organisms, including plants, to develop efficient mechanisms for maintenance of the genome integrity. DNA repair processes have been characterized in bacterial, fungal, and mammalian model systems. The description of these processes in plants, in contrast, was initiated relatively recently and has been focused largely on the model plant Arabidopsis thaliana. Consequently, our knowledge about DNA repair in plant genomes - particularly in the genomes of crop plants - is by far more limited. However, the relatively small size of the Arabidopsis genome, its rapid life cycle and availability of various transformation methods make this species an attractive model for the study of eukaryotic DNA repair mechanisms and mutagenesis. Moreover, abnormalities in DNA repair which proved to be lethal for animal models are tolerated in plant genomes, although sensitivity to DNA damaging agents is retained. Due to the high conservation of DNA repair processes and factors mediating them among eukaryotes, genes and proteins that have been identified in model species may serve to identify homologous sequences in other species, including crop plants, in which these mechanisms are poorly understood. Crop breeding programs have provided remarkable advances in food quality and yield over the last century. Although the human population is predicted to "peak" by 2050, further advances in yield will be required to feed this population. Breeding requires genetic diversity. The biological impact of any mutagenic agent used for the creation of genetic diversity depends on the chemical nature of the induced lesions and on the efficiency and accuracy of their repair. More recent targeted mutagenesis procedures also depend on host repair processes, with different pathways yielding different products. Enhanced understanding of DNA repair processes in plants will inform and accelerate the engineering of crop genomes via both traditional and targeted approaches.

Keywords: Arabidopsis, crop plants, DNA damage, DNA repair, mutagenesis 


\section{INTRODUCTION}

Cellular DNA of living organisms normally suffers damage which may arise endogenously or can be induced by a variety of external genotoxins including ultraviolet light, ionizing radiation, and chemical mutagens. The most frequently encountered injuries to the DNA- often induced through inevitable errors of internal metabolism- are modifications to nucleotides, intra- or interstrand cross-links, and breaks of the phosphodiester bonds. If damaged DNA is not repaired it may have difficulties in being properly organized, replicated, or transcribed. The impairment of such essential molecular processes affects cellular functionality and may disturb the normal development of the whole organism (Britt, 1996; Polyn et al., 2015). Plants are particularly vulnerable to the DNA damaging factors present ubiquitously in the air, soil, and water. Hence, they have evolved a complex network of mechanisms of DNA damage detection and repair dedicated to ensure their genomic stability through removal of the DNA lesions and reconstitution of the original genetic information (Bray and West, 2005; Yoshiyama et al., 2013). An intrinsic feature of certain DNA repair pathways is that they are not errorfree, leading to potentially transmissible mutational alterations. The error-prone nature of some DNA repair mechanisms, however, increases the genetic diversity and variability of the populations, thus contributing to the evolution of plant genomes (Schuermann et al., 2005). Chemical or radiationinduced mutagenesis has been a powerful tool for creation and improvement of economically important crop varieties (Parry et al., 2009; Forster and Shu, 2012). The mutations occurring in the plant genome after particular mutagenic treatment are determined by both the spectrum of lesions generated by the mutagen and the specificity and efficiency of DNA repair pathways involved. Therefore, our understanding of DNA repair mechanisms and their regulation in plants is an essential requirement for the effective utilization of mutation technologies in future crop improvement.

It is generally accepted that the choice of a repair pathway and its action is primarily dependent on the type of the cell, its proliferation status, cell cycle stage, as well as on the type of the lesion and its genomic context (Britt, 1999). Plants do not choose where they live and cannot escape unfavorable environmental impacts. Therefore, they need strictly controlled but flexible DNA repair mechanisms responsive to the changing environment. Indeed, common external factors such as light regimes, temperature or water availability were shown to dictate the specific activation and efficiency of certain DNA repair pathways, such as recombination or photorepair in various plants (Li et al., 2002; Boyko et al., 2005; Chang et al., 2008). Rapidly dividing and differentiated cells of different plant organs do not equally utilize the whole available repertoire of DNA repair mechanisms (Kimura et al., 2004; Boyko et al., 2006; Yang et al., 2010). Moreover, the capability of plants to maintain their genomic integrity was shown to decrease with plant age mainly due to a reduction in the efficiency and relative contribution of the employed DNA repair pathways (Golubov et al., 2010).

With some exceptions plants have been shown to possess all common DNA repair mechanisms which have been initially described to a greater extent in the other eukaryotic systems, such as yeast and mammals (Britt, 2002). Photoreactivation of UV-induced DNA damage is one of the primary DNA repair mechanisms needed by plants on a daily basis because of their inherent necessity and exposure to solar light. The two classical forms of excision repair, base (BER) and nucleotide (NER), often regarded as "dark repair", are also available for the plant genome suffering various types of DNA lesions (Rastogi et al., 2010). MMR has been implicated in the removal of incorrectly paired nucleotides and the UV-induced photolesions from the genome of higher plants (Culligan and Hays, 2000; Lario et al., 2011). The main DNA double-strand break repair pathways - HR and NHEJ have been shown to be essential in plants for the preservation of their genetic stability (Puchta and Hohn, 1996; Waterworth et al., 2011). Some of the repair mechanisms as photoreactivation are highly specialized for a particular damage, however, others, like excision or recombination pathways may deal with a variety of lesions (Ries et al., 2000a).

Significant progress in elucidation of DNA damage repair in higher plants has been made mainly utilizing the small dicot Arabidopsis thaliana as a model (Hays, 2002). The isolation and characterization of the first plant DNA repair genes involved in the photorepair, excision repair, HR and NHEJ have been initially based on the homologous sequence information available from other organisms (Batschauer, 1993; Britt et al., 1993; Santerre and Britt, 1994; Ahmad et al., 1997; Jiang et al., 1997a; Doutriaux et al., 1998; Garcia et al., 2000; Hartung et al., 2000; Liu et al., 2000; Osakabe et al., 2002; Tamura et al., 2002; West et al., 2002, etc.). During the last decade significant progress has also been made in the molecular characterization of the repair pathways and genes mediating these processes in important crop plants such as rice, spinach, cucumber, tomato, wheat, barley, etc. The headlong progress of molecular technologies has expanded the number of sequenced crop genomes and thus contributed to the advancements made in the field of plant DNA repair as well (Singh et al., 2010; Kim et al., 2015). In addition to Arabidopsis, rice is the other higher plant with relatively well characterized DNA repair mechanisms with respect to the influence of various developmental and environmental factors on their activation and efficiency, as well as regarding the identification and regulation of genes involved in the DNA repair and protection mechanisms (Ueda and Nakamura, 2011). The sequence of the rice genome has been useful for the efficient identification of orthologous genes, regulatory regions and gene functions in other cereals (Goff et al., 2002). For example, currently identified barley and wheat genes display $\sim 80 \%$ homology, at the nucleotide level, to their rice counterparts thus substantiating the usefulness of rice homologous sequences for identification of the DNA repair-associated genes in other monocots. The intensive research performed on Arabidopsis and rice has enormously increased the current knowledge on the molecular nature and regulation of DNA damage and repair mechanisms in plants. However, such studies should be expanded to include a larger number of model and crop species if we want to have a clearer picture of the capacity of plant genomes to overcome the biological impacts of different genotoxins and to adapt to the changing environmental stress conditions. 


\section{DNA DAMAGE INDUCED BY ENDOGENOUS AND EXOGENOUS FACTORS}

DNA lesions are divided into two main categories: singleand double-stranded. The first category is comprised of lesions disturbing only one DNA strand, such as oxidized or alkylated base damage, base loss, DNA adducts, intra-strand cross-links, DNA photoproducts and single-strand DNA breaks (SSBs). The second category includes lesions affecting both DNA strands, such as inter-strand cross-links and double-strand DNA breaks (DSBs), the latter being the most severe type of DNA damage in the eukaryotic genome (Figure 1).

\section{Endogenously Arising DNA Lesions}

A major source of endogenous DNA lesions is the intracellular metabolism which increases the concentration of free radicals in the environment surrounding the DNA; in plants, ROS are especially ubiquitous in the chloroplasts and mitochondria (Sharma et al., 2012). AP sites may arise by spontaneous hydrolysis of the $\mathrm{N}$-glycoside bond or as intermediates resulting from the repair of deaminated, alkylated or oxidized bases (Cooke et al., 2003; Tuteja et al., 2009). Moreover, all DNAassociated processes involved in the transmission, expression and maintenance of genetic information have the potential to cause SSB or DSB in DNA (Bessho, 2003; Edlinger and Schlögelhofer, 2011; Montecucco and Biamonti, 2013).

\section{DNA Lesions Caused by Exogenous Damaging Factors}

\section{Alkylating Agents}

Monofunctional alkylators such as MMS and EMS are the chemical agents most widely utilized to obtain mutagenized plants aimed at both crop improvement and reverse genetics studies (Till et al., 2003; Natarajan, 2005). Alkylating agents

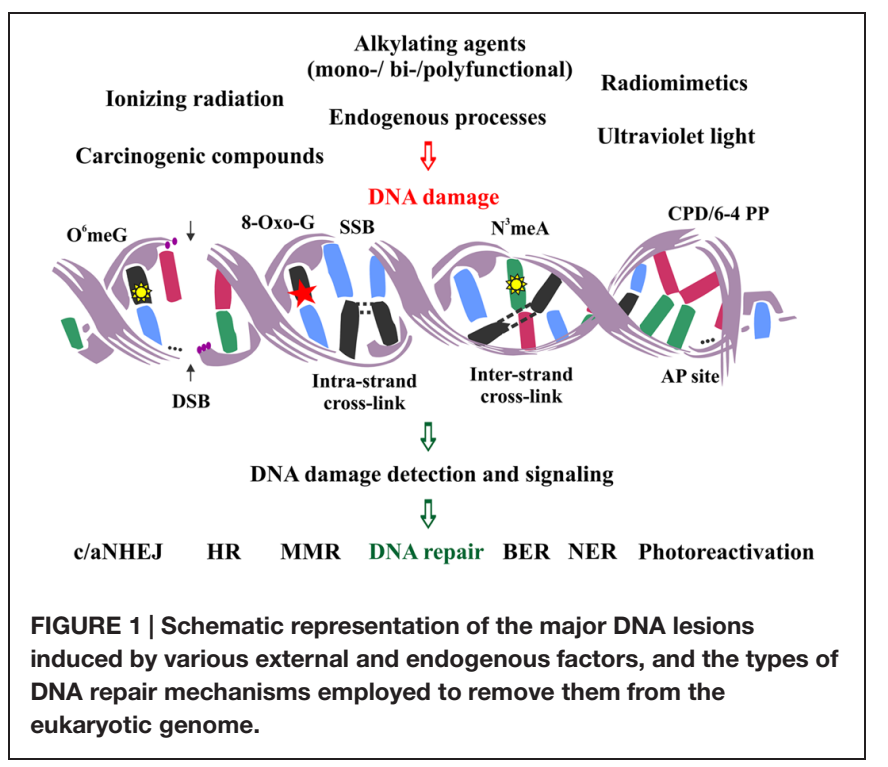

methylate the DNA bases, mainly at their O- and N-positions generating small base damage as $\mathrm{O}^{6}$-methylguanine $\left(\mathrm{O}^{6}\right.$-meG), $\mathrm{N}^{7}$-methylguanine or $\mathrm{N}^{3}$-methyladenine (Shrivastav et al., 2010). $\mathrm{Bi}$ - and polyfunctional alkylating agents as well as many carcinogenic compounds form intra-strand cross links between adjacent guanines or bulky adducts to nucleotides which significantly distort the conformation of the DNA molecule. Psoralens and mitomycin $\mathrm{C}$ can also induce inter-strand crosslinks connecting the two opposite DNA strands thus effectively blocking the replication and transcription machineries (De Silva et al., 2000).

\section{lonizing Radiation}

Ionizing radiation in the form of gamma- and X-rays as well as ion-beams is another commonly employed DNA damaging agent with high mutagenic potential in plants (van Harten, 1998). It produces a large number of lesions through a direct ionization of the DNA molecule or indirectly via an initial interaction with water resulting in the subsequent radiolysis and production of highly reactive species, such as hydroxyl radicals $\left(\mathrm{OH}^{\bullet}\right)$, free electrons (e-) and hydrogen radicals $\left(\mathrm{H}^{\bullet}\right)$ (Alpen, 1998). In the case of a direct event the high-energy deposition of IR generates DSB which leads to DNA fragmentation. IR-induced DSBs frequently have modified termini such as $5^{\prime}$ hydroxyl, $3^{\prime}$ phosphate, and $3^{\prime}$ glycolate, which need processing to make them compatible for ligation (Schärer, 2003). Oxidation products (8-oxoguanine, thymine glycols, etc.), base loss (AP lesion of "regular" or "oxidized types") as well as SSB are amongst the lesions generated via secondary DNA ionization. Moreover, IR induces multiple damaged sites representing two or more closely localized lesions on the same or the opposite DNA strands (Shikazono et al., 2009), which usually involve SSB with damaged termini accompanied by modified or damaged bases and deoxyribose moieties with a significantly higher frequency than the frank DSB (Sutherland et al., 2000). Recent research shows that such a cluster might transform to DSB as a result of excision repair, but this probability depends on the local chromatin environment (Cannan et al., 2014). It was generally thought that IR-induced DSBs are spread rather randomly in the genome; however, an accumulating body of evidence reveals the influence of chromatin organization and nuclear matrix proteins on DSB distribution (Lavelle and Foray, 2014).

\section{Radiomimetic Agents and REs}

Double-strand breaks are also produced by a variety of radiomimetic agents, so-called because of their ability to act on the DNA by mimicking the effects of IR. The anticancer drug BLM which is frequently utilized in the studies of DSB formation and repair in mammalian cells has been shown to effectively generate DSB in many plant systems as well. That is why numerous DNA repair assays based on the BLM action have been introduced in a variety of plant species (West et al., 2002; Manova et al., 2006; Georgieva and Stoilov, 2008; Kozak et al., 2009; Stolarek et al., 2015a,b). BLMs are a family of glycopeptides which cannot diffuse freely through the cellular membranes due to their hydrophilic properties, but are transferred into the cell by a receptor-mediated endocytosis (Chen and Stubbe, 2005). 
A single BLM molecule can cause breakage in the doublestranded DNA thus generating blunt DSB ends or termini with non-complementary single-base extensions. In addition, abasic sites with closely opposed SSB can also result from the BLM action in a frequency exceeding that expected by the coincidence of two independent damaging events. Oxygen levels of the microenvironment could modify the type of BLM-generated DNA damage - a lack of $\mathrm{O}_{2}$ favors the formation of AP site, whereas the presence of $\mathrm{O}_{2}$ facilitates formation of a DSB with $5^{\prime}$-phosphate and $3^{\prime}$-phosphoglycolate ends (Povirk and Finley Austin, 1991). The action of BLM is modulated by the local nucleosome structure and higher-order chromatin organization (Smith et al., 1994), leading to the preferential DNA breakage in the linker DNA of mammalian and plant cells (Kuo, 1981; Manova et al., 2006).

Restriction endonucleases produce only DSBs, which may be of "blunt" or "cohesive" type, but are always readily ligatable with $5^{\prime}$-phosphate and 3'-hydroxyl groups (Bryant, 1990). REs have a high clastogenic activity on the genomes of mammals and plants (Obe et al., 1995; Stoilov et al., 2000; Manova and Stoilov, 2003). The unique selection ability of rare-cutting endonucleases has been used to develop highly specialized transgenic systems in order to monitor somatic HR in various plants such as Arabidopsis, tobacco and rice (Puchta et al., 1995; Puchta and Hohn, 2012). The more recently developed chimeric nucleases designed to target particular genomic locations and introduce DSB at specific DNA sequences have the potential to broaden the studies of DSB rejoining in plant genomes (see later).

\section{Ultraviolet Radiation}

Ultraviolet radiation, being a component of sunlight, is the most common genome-damaging agent ubiquitously found on earth (Britt, 2004). It belongs to the electromagnetic radiation spectrum with wavelengths ranging from 100 to $400 \mathrm{~nm}$. There are three ranges of UV radiation: short UV-C (100-280 nm), which is the most harmful for the genetic material as it is directly absorbed by the DNA, middle-range UV-B (280-315 nm) which is the main DNA damaging component of the solar light, and long wavelength UV-A (315-400 nm).

UV light generates two major types of lesions in DNA CPDs and 6-4 PPs, whose relative proportion and non-random distribution within the eukaryotic genome depends on the sequence composition and chromatin structure (Pfeifer, 1997; Kwon and Smerdon, 2005; Law et al., 2013). In plants the CPDs may account for up to $90 \%$ of all pyrimidine dimers induced upon exposure to UV-B (Dany et al., 2001). In the case of CPD the covalent bonds are formed between the C-5 and C- 6 carbon atoms of the adjacent pyrimidine bases, usually between TpT and less frequently between $\mathrm{TpC}$ and $\mathrm{CpC}$ sequences (Durbeej and Eriksson, 2003). The 6-4 PPs are typically formed between the carbon atoms at C-6 and C-4 positions of an adjacent TpC dinucleotide (Pfeifer et al., 1991). The presence of CPDs has the potential to block the transcribing complexes thus completely altering the relative expression pattern of genes (Tornaletti et al., 1999). During replication, however, dimers can be bypassed by specialized translesion DNA polymerases which increase the cellular tolerance to UV damage, also in plants (Britt, 1995; Curtis and Hays, 2011; Nakagawa et al., 2011).

$\mathrm{UV}$ radiation may also induce oxidative DNA damage, mediated predominantly, but not exclusively, by endogenous photosensitizers that generate free radicals upon their activation. The genotoxic effects of oxidative DNA damage were clearly demonstrated in mammalian cells (Roldán-Arjona et al., 2002). Although rare, there are studies showing the presence of UVinduced oxidative DNA lesions in plants (Watanabe et al., 2006). As in plants pyrimidine dimers are primarily repaired by photoreactivation, it might be speculated that oxidative DNA damage, known to be eliminated by the error-prone excision repair, could also contribute to the UV-associated mutagenicity and plant genomic instability.

\section{DNA REPAIR PATHWAYS IN MODEL AND CROP PLANTS - NATURE AND EFFICIENCY, GENETIC CONTROL, AND AGRICULTURAL IMPORTANCE}

\section{Photoreactivation}

Photoreactivation is a rare example of a simple and errorfree pathway for the reversal, rather than the removal of DNA damage. It is performed by a single, lesion-specific enzyme called photolyase. It is thought to be the first DNA repair pathway to have evolved in early life forms, which is still being maintained in such various organisms as bacteria, yeast, plants, and animals, but has been evolutionarily lost by the placental mammals (Lucas-Lledó and Lynch, 2009). Two different types of photolyase enzymes have been established in plants which are specialized to reverse selectively the 6-4 photoproducts (6-4 photolyase type) or the CPD (class II photolyase). Photolyases bind to their specific damage-substrate within the doublestranded DNA in a light-independent manner. However, in order to get energy for correcting the lesion they need to be excited by photons from the blue or near UV-A spectrum (Brettel and Byrdin, 2010) (Figure 2). Subsequently, the electron is transferred from the CPD photolyase chromophore to the lesion and after splitting the dimer's covalent bonds, it is returned back to restore the catalytically active state of the cofactor (Thiagarajan et al., 2011). The exact chemistry of the photorepair reactions differ between the two photolyase types, however, the final products are monomerized pyrimidine bases and unchanged nucleotide sequence (Yi and He, 2013). The error-free nature of photoreactivation makes it the preferable and most effective mechanism utilized by plants to quickly reduce the negative effects of DNA photodimers generated upon their normal exposure to solar radiation (Dany et al., 2001; Britt, 2004). However, inability of the cell to photorepair may lead to a switch in the transcriptional response of UV stressed plants activating the completely different DNA repair pathway such as HR (Molinier et al., 2005).

Based on the UV-B sensitive Arabidopsis mutants deficient in either CPD or 6-4 PP repair two different plant photorepair genes have been identified - PHR 1 coding for the CPD photolyase 


\section{Photoreactivation}

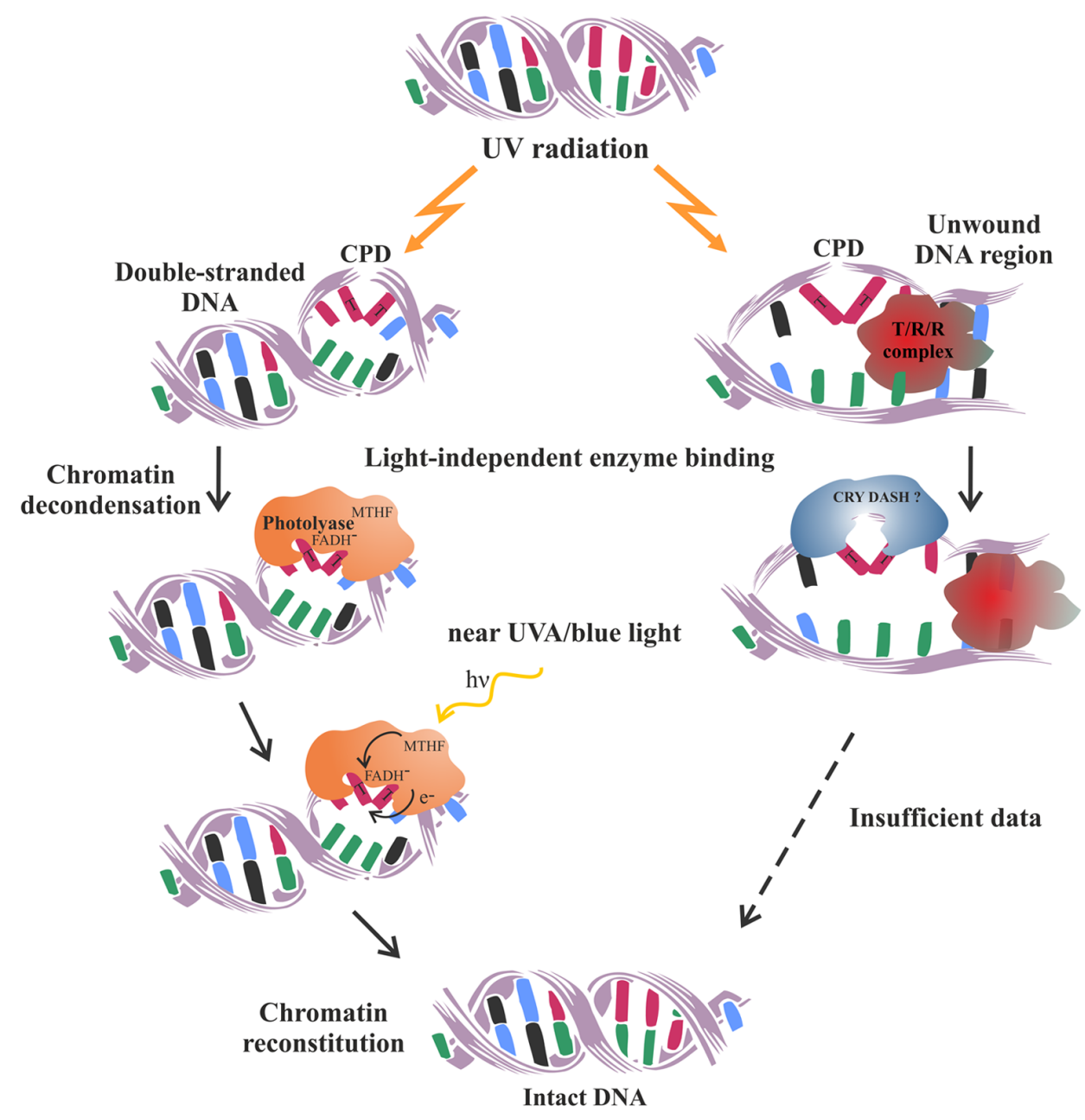

FIGURE 2 | Schematic representation of the photoreactivation mechanism utilized by plants to repair UV-induced pyrimidine dimers. On the left is schematized the classical well characterized process of CPD photoreactivation in double-stranded DNA. On the right is presented a hypothetical mode of CPD photoreactivation, which might operate within the open DNA regions generated during transcription, replication and repair processes. It is thought to be mediated by the DASH chryptochromes, based on their ability to photoreactivate CPD in single-stranded DNA (Pokorny et al., 2008). Future research is needed to prove or reject such an intriguing concept. T/R/R complex - transcription, replication or repair complex.

and UVR3 which encodes the 6-4 photolyase (Britt et al., 1993; Jiang et al., 1997b; Landry et al., 1997; Nakajima et al., 1998). Effective light-dependent repair of DNA photolesions has been demonstrated in all plants investigated so far and the lesionspecific photolyases identified in Arabidopsis (Pang and Hays, 1991; Chen et al., 1994; Ahmad et al., 1997) have also been cloned and/or reported to operate in a variety of other plant species like maize (Stapleton et al., 1997), wheat (Taylor et al., 1996), white mustard (Batschauer, 1993), cucumber (Takeuchi et al., 1998), spinach (Yoshihara et al., 2005), alfalfa (Quaite et al., 1994), rice (Hirouchi et al., 2003), soybean (Yamamoto et al., 2008), barley (Manova et al., 2009), etc. In view of the importance of the photorepair mechanism for plant growth and development under UV exposure it is not surprising that the CPD photolyase has become one of the most intensively studied DNA repair genes in higher plants. Photolyases belong to a special category of proteins, the photolyase/cryptochrome family, containing flavin as a cofactor and, depending on the species, a "second" chromophore acting as a photoantenna (Thompson and Sancar, 2002). Plant CPD photolyases analyzed so far, particularly the Arabidopsis and rice enzymes, show similar chromophore compositions, consisting of both a reduced FADH and a pterinlike cofactor (Waterworth et al., 2002; Teranishi et al., 2008).

The cryptochromes work mainly as photoreceptors regulating plant development as they do not possess the standard photorepair activity characteristic of the photolyase proteins. More recently, it has become evident that a special subclass of these flavoproteins actually has DNA-binding and photorepair activity, but only on single-stranded and/or loop DNA structures. These intriguing observations have inspired the hypothesis that 
DASH-type cryptochromes might be involved in the repair of the locally unwound DNA regions generated by the active matrix processes such as replication, transcription, and DNA repair (Selby and Sancar, 2006; Pokorny et al., 2008).

Chromatin organization affects not only the formation, but also the repair of UV-induced pyrimidine dimers. In yeast the access of photolyase proteins to the UV-damaged DNA was inhibited in the compacted chromatin, whereas the local nucleosome unpacking and repositioning facilitated photoreactivation (Thoma, 2005). It has been recently shown that histone-binding proteins of the ASF group are essential for CPD repair in Arabidopsis specifically under light conditions (Lario et al., 2013). Moreover, chromatin factors and histone acetylation have been important prerequisites for UV damage removal in both Arabidopsis and maize, suggesting an important role of chromatin restructuring for the effective photorepair process also in plants (Campi et al., 2012).

Currently the data obtained in different plant species concerning the distribution of photolyase proteins and their activities within the intracellular compartments are rather controversial. A number of studies have shown that CPD photolyase is present exclusively in the nucleus thus implying that extranuclear DNA in plant mitochondria and chloroplasts cannot be photoreactivated. Indeed, fractionated extracts from spinach chloroplasts were found to be free of the photolyase activity otherwise contained in whole leave preparations (Hada et al., 2000). The lack of CPD repair from spinach organelles confirmed the earlier findings showing that young Arabidopsis seedlings were able to remove CPD only from the nuclear genome, but not from the chloroplast and mitochondrial DNA sequences (Chen et al., 1996). In line with the idea, in Arabidopsis it was demonstrated that the CPD photolyase protein is transported only into the nucleus, but not in the chloroplasts (Kaiser et al., 2009).

On the other hand, light-dependent repair with varying efficiency was found in the individual soybean and maize genes localized not only in the nucleus but also in the chloroplast and mitochondrial genomes (Cannon et al., 1995; Stapleton et al., 1997). The fully developed Arabidopsis leaves also repaired CPDs and 6-4 PPs in the nuclear and chloroplast DNA upon prolonged blue light exposure and restored the replication of both nuclear and organellar genomes. These observations illustrate that young and mature plants may differ in their DNA repair capacity, which in turn may affect their overall tolerance to UV stress (Draper and Hays, 2000). Moreover, data obtained in rice reveal that CPD photolyase is localized not only in the nucleus, but is also active in the mitochondria and plastids. The presence of CPD photolyase in the organelles allows the rice leaf cells to employ photoreactivation to restore the integrity of extranuclear DNA after UV-B exposure (Takahashi et al., 2011). Phosphorylation, particularly at serine-7, was found to be an important modification of rice CPD photolyase, regulating protein translocation within the cellular compartments (Teranishi et al., 2013). In rice nuclei and chloroplasts the photolyase is mainly present in its phosphorylated form, whereas in the mitochondria the major part of the protein is unphosphorylated. Recently, unique sequences targeting rice
CPD photolyase to the mitochondria have been identified in the C-terminal region of the protein and validated as functionally important (Takahashi et al., 2014). Therefore, further studies will reveal whether the access of plant photolyases to the organellar genomes is species-specific, or whether it depends on the developmental stage of the plant, as well as on the organ or tissue affected, or there are other factors at the molecular level which might control the presence and activity of plant photolyase proteins within the nuclear and extranuclear plant genomes.

\section{Photorepair and Its Impact on Agriculture}

The inhibitory effect of the UV-component of natural light on Arabidopsis growth affected plant height and the rosette diameter in both wild-type and the DNA repair mutants, and those defective in the PHR1 were found to be most sensitive to the daily UV-B exposure (Britt and Fiscus, 2003). Regarding crop plants, intensive research has focused on the variations of CPD photorepair efficiency as a primary determinant of UV-B tolerance affecting the development of individual rice cultivars. The agriculturally valuable and therefore widely cultivated variety Norin1 was more sensitive to UV-B radiation compared to the Sasanishiki cultivar. Notably, the lower capacity of plant leaves to repair CPDs was the primary cause of the reduced productivity and growth of Norin1 (Hidema et al., 1997). It was shown that even a single nucleotide variation changing Gln-126 (in Sasanishiki) to Arg (in Norin 1) may generate structural alterations in the photolyase protein, thus affecting the stability of the CPD-photolyase complex. The resulting decrease in the repair activity of the enzyme thus explains the significant differences in the UV resistance between the two cultivars (Hidema et al., 2000; Teranishi et al., 2004). Moreover, spontaneously occurring variations in other crucial domains of CPD photolyase protein have changed the photorepair ability of many cultivated and wild rice genotypes, thus creating differences in their UV-B sensitivity finally manifested as reduced growth and productivity (Hidema et al., 2005; Iwamatsu et al., 2008). Combined these studies demonstrate that UV tolerance is a vital characteristic of the contemporary plant cultivars and DNA repair, and photolyase in particular, might be an important target for modification to improve economically important crops in modern breeding programs (Hitomi et al., 2012).

The capability of plants to photoreactivate UV-induced pyrimidine dimers depends also on the available amounts of the photolyase protein within the damaged cell. The first indication of the influence of light environment on the transcriptional regulation of plant photolyase genes came from the observation that the etiolated plants had a lower capacity to repair CPDs than the de-etiolated. On the other hand, the 6-4 photoproducts were repaired very efficiently not only in the green, but also in the etiolated Arabidopsis plantlets. A lack of gene transcripts and CPD photolyase activity in the dark-grown seedlings has been reported in several plants such as mustard, Arabidopsis and spinach (Batschauer, 1993; Chen et al., 1994; Yoshihara et al., 2005). Within the first hours of light exposure the expression 
of PHR1 and the accumulation of functional protein increased drastically. The light-dependent regulation of PHR1 possibly underlined the diurnal fluctuations of the photorepair activity measured in cucumber leaves (Takahashi et al., 2002). The continuous light exposure, however, may finally reduce the CPD photolyase transcript levels if not supplemented with a UV-B component (Waterworth et al., 2002). Intense UV-B radiation also enhanced the expression of PHR1 gene in Arabidopsis and cucumber, but at the same time inhibited the activity of the protein in the latter (Ries et al., 2000b; Takeuchi et al., 2007). In fact, etiolated plant tissues may contain certain amounts of CPD photolyase transcripts and activity allowing initiation of CPD repair immediately upon their exposure to visible light (Takeuchi et al., 2007; Castells et al., 2010). In Arabidopsis, the dark inhibition of photorepair gene expression is maintained through the photomorphogenic repressors AtDET1 and AtCOP1 until their negative action is alleviated during de-etiolation. However, the transcriptional induction of photolyase genes, both AtPHR 1 and AtUVR3, is further stimulated by the HY5 and HYH transcription factors (Castells et al., 2010). A key player of plant response to UV-B is the recently identified UV-B specific photoreceptor AtUVR8 which manages a downstream signaling cascade involving COP1 and HY5, which in turn, control the expression of many genes related to both plant UV-protection and photomorphogenic response (Tilbrook et al., 2013). In line, the Atuvr8-2 mutant is unable to induce PHR1 gene expression, which is normally found in the wild-type plants exposed to low UV-B levels (Brown and Jenkins, 2008). Another report also shows that under normal conditions AtPHR1 is targeted by the transcriptional repressor E2Fe/DEL1 involved in the regulation of the endoreduplication potential of the cell, but this suppression is alleviated upon UV-B exposure allowing the induction of AtPHR1 (Radziejwoski et al., 2011).

The above results demonstrate that the manipulation of plant CPD photolyase at the transcriptional level might be a promising approach for the generation of UV resistant plants. Indeed, transgenic Arabidopsis lines overexpressing CPD photolyase showed an improved repair capacity and enhanced UV tolerance (Kaiser et al., 2009). On the other hand, by silencing the same gene Yoshihara et al. (2008) were able not only to decrease the UV-B tolerance of the knocked-down plants, but also to increase the rate of transitions and frameshift mutations in the Arabidopsis genome. Hence, photolyase genes seem valuable for the modern agriculture for at least two reasons - the first is to improve the UV tolerance and productivity of the economically important cultivars, and the second might be to aid mutagenesis studies by enhancing the efficiency of mutation induction in the plant genome.

\section{Direct Repair by DNA Alkyltransferases}

Another form of a direct DNA damage repair is the specific processing of alkylated bases executed by the enzyme called AGT. The repair mechanism includes direct transfer of the alkyl group from the lesion to the cysteine residue located in the active center of the enzyme; as the reaction is irreversible the inactivated protein undergoes further proteasome degradation. AGT is a compact single chain protein which scans the genome and provides fast repair of the lesions due to its efficient binding into the minor groove of DNA (Pegg, 2011). It is believed that the enzyme can target itself to the sites of active transcription, where it ensures the error-free repair of $\mathrm{O}^{6}$ meG especially in the transcriptionally active regions (Ali et al., 1998). The non-repaired $\mathrm{O}^{6}-\mathrm{meG}$ can be bypassed during both replication and transcription giving rise to transition mutations and altered mRNA molecules, respectively (Iyama and Wilson, 2013). In human cells, AGT functioning is essential to prevent the accumulation of altered transcripts and mutant proteins (Burns et al., 2010). AGTs are ubiquitously present from bacteria to humans; the only organisms lacking this repair enzyme are fission yeast and plants (Pegg, 2011). Indeed, the search for AGT homologs in both model and crop plants has been largely unsuccessful so far (Costa et al., 2001). In plants $\mathrm{O}^{6}$ $\mathrm{meG}$ is a preclastogenic lesion associated with the formation of chromosomal aberrations (Baranczewski et al., 1997a). In Vicia faba root tips, however, the reduction of chromatid aberration frequency has been correlated with an effective removal of $\mathrm{O}^{6}$ $\mathrm{meG}$ implying the presence of rapid adaptive mechanisms against this lesion in plant genome (Baranczewski et al., 1997b). It is therefore quite probable that other DNA repair pathways efficiently substitute the lack of AGT activity in plants and recent research implicates BER as such a possible candidate.

\section{Base Excision Repair}

Base excision repair is active on a wide range of lesions, such as damaged or modified bases as well as naturally occurring AP sites. It is initiated by damage-specific DNA glycosylases which cleave the $\mathrm{N}$-glycosidic bond and remove the affected base generating an abasic site. AP endonuclease or AP lyase activities are further necessary for processing of the resultant AP site. Subsequently the repair reaction may proceed by either a "short" or a "long" patch mechanism depending on the type of lesion and the enzyme engaged. In mammalian cells, the "short" mode of BER employs the activity of DNA polymerase $\beta(\operatorname{pol} \beta), \mathrm{XRCC} 1$ and Ligase III which accomplish the repair by excision of only one nucleotide. The "long-patch" BER involves the removal of up to 10 nucleotides surrounding the lesion and relies on the activity of polymerase complex $\delta / \varepsilon-\mathrm{PCNA}$ FEN1. It is important to note that single strand DNA breaks are unavoidable intermediates during BER, and as such they may become substrates of other repair mechanisms such as NER and recombination repair (Memisoglu and Samson, 2000).

Up to now, several lesion-specific DNA glycosylases have been identified in plants. Arabidopsis 3-methyladenine-DNA glycosylase, the first cloned plant DNA repair gene, was shown to remove the alkylated DNA lesions induced by MMS treatment (Santerre and Britt, 1994). In whole-cell extracts isolated from Arabidopsis the uracil containing DNA is repaired by the BER pathway employing enzymes from the uracil-DNA glycosylase family. Notably, both BER modes may occur after the initial incision steps despite the lack of pol $\beta$ and Ligase III homologs in plants, and the repair reactions are finalized by the ligating activity of AtLIG1 (Córdoba-Cañero et al., 2009, 2011). In fact, in vitro monitoring of DNA repair reactions performed with cellular extracts isolated from Arabidopsis or 
other plants have been extremely useful to describe many of the structural and functional aspects of plant BER. Short-patch BER was revealed as an essential DNA repair pathway in plant mitochondria, at least for the removal of uracil, where uracilDNA glycosylase activity was found associated predominantly with the organellar membrane in both the model and crop species (Boesch et al., 2009). In A. thaliana the AtFPG and AtOGG1 enzymes showed glycosylase/lyase activities to initiate the repair of oxidative lesion 8-oxoG and endogenous AP sites, and the generated intermediates later became substrates of the ZDP DNA 3 '-phosphatase and ARP endonuclease. In line with their proposed role in the repair of oxidized bases, inactivation of the AtFPG and AtOGG1 genes increased the level of oxidative DNA lesions in both the nuclear and mitochondrial genomes, whereas impairment of AtARP and AtZDP functions accelerated seed aging (Córdoba-Cañero et al., 2014). The putative AtPol $\lambda$ has been implicated in the synthesis step of "long-patch" BER in Arabidopsis, based on the previously identified X-family DNA polymerase Pol $\lambda$ from rice, although a contribution of yet unidentified plant DNA polymerases has not been excluded (Córdoba-Cañero et al., 2009; Uchiyama et al., 2009). As mentioned earlier, experimental evidences obtained so far show that LIG1 is the only ligase which can be unambiguously associated with both the "short" and the "long" patch BER in plants (Córdoba-Cañero et al., 2011).

Base excision repair is also implicated in the epigenetic control, as it is actively involved in the removal of $5-\mathrm{mC}$ and its replacement with non-methylated $\mathrm{C}$ in eukaryotes, including plants. DNA methylation is an epigenetic modification associated with a compacted chromatin state which limits the accessibility of transcription factors or repair proteins to DNA. Therefore, improper BER functioning may prevent demethylation, and hence may affect gene regulation and activity of other DNA damage repair pathways by altering the expression of repair-associated genes. Several proteins have been recognized as being essential for different stages of BER-mediated demethylation processes in plants, such as the bifunctional DNA glycosylase/lyase ROS1, removing the methylated base and cutting the DNA strand, the DNA phosphatase ZDP involved in the processing of resulting intermediates as well as the Arabidopsis homolog AtXRCC1 which stimulates 3'end cleaning and ligation steps (Martínez-Macías et al., 2013).

The PCNA homologs have been identified in Arabidopsis and various crop species, and some of them were found to possess a second functionally active copy of the gene. The plant PCNA proteins display many structural and functional similarities to those of other organisms supporting their involvement in the excision repair as well as in the replicative DNA synthesis pathways in plants (Strzalka and Ziemienowicz, 2011). Indeed, it was shown that the activities of both OsFEN1 and OsPol $\lambda$ proteins in rice were enhanced by their interaction with OsPCNA, which is consistent with the active role of these enzymes in plant BER. Gene expression studies in rice coordinated BER activity with cell proliferation, as high levels of OsPCNA, OsFEN1- $a$, and OsPol $\lambda$ transcripts were detected mainly in the developing rice tissues but not in the mature leaves, especially after DNA damaging treatment (Kimura et al., 2004; Uchiyama et al., 2004). In Medicago truncatula, upregulation of $M t O G G 1$ and $M t F P G$ glycosylases was found during seed imbibition which coincided with water up-take and ROS production (Macovei et al., 2011). All of the above results imply that BER is extremely important for seed longevity as it helps the germinating embryo to repair oxidative DNA lesions accumulated during seed storage. Therefore, further knowledge on these mechanisms would help to improve preservation of the seeds and find new ways to maintain their germination potential. Although, BER activity in the mature plant organs might be less essential for the maintenance of DNA integrity, the involvement of BER in the establishment of epigenetic pattern of the genome implies important functioning of this pathway in transcriptional control at different stages of plant development.

\section{Nucleotide Excision Repair}

Nucleotide excision repair is a general repair mechanism employed by both prokaryotic and eukaryotic cells to remove a variety of structurally different DNA lesions. The main substrates of NER are UV-induced photoproducts and other bulky DNA adducts that generate substantial conformational changes in DNA. The efficiency of NER varies within the different genomic locations and depends on the type of DNA lesion. Two distinct subpathways of NER exist - Global genomic repair (GGR) and Transcription-coupled repair (TCR). GGR is a whole genome repair pathway influenced by the chromatin structure and DNAbound proteins, whereas TCR specifically accelerates the removal of transcription-blocking lesions from the template DNA strand of the highly expressed genes (Hanawalt, 2002). The two NER modes utilize specific factors but also share repair proteins and the main difference between them is in the system employed to sense the damage, whereas the later stages proceed in a similar way (Figure 3).

In animals GGR is initiated by the heterotrimeric complex Xeroderma Pigmentosum group C (XPC)/HR23B/Centrin2 which scans the genome and detects the damaged region based mainly on the distortion the particular lesion generates in the DNA double-helix, rather than on its chemical nature. The complex may be assisted by the heterodimer UV-DDB (composed of DDB1 and DDB2 subunits) helping to find lesions such as CPD, which only slightly alter the structure of DNA (Sugasawa, 2009). RPA, XPA, and XPG are then recruited along with the multiprotein complex TFIIH employed to verify the damage and identify which of the DNA strands is actually affected. TFIIH is also a component of the RNA polymerases I-III holoenzymes where it is crucial for transcription initiation and DNA unwinding during the early elongation step. Due to its complex dynamic structure and multifunctionality TFIIH is able to coordinate transcription and DNA repair, and may also relate these processes to the cell cycle control (Mydlikova et al., 2010). The recruitment of TFIIH during NER allows opening of the DNA duplex, which is performed by its key helicase subunits XPB and XPD, each of them bound to a different DNA strand. Their positioning within TFIIH determines the asymmetry and length of the opened DNA region; after verification the selected strand is 


\section{Global Genome Repair}
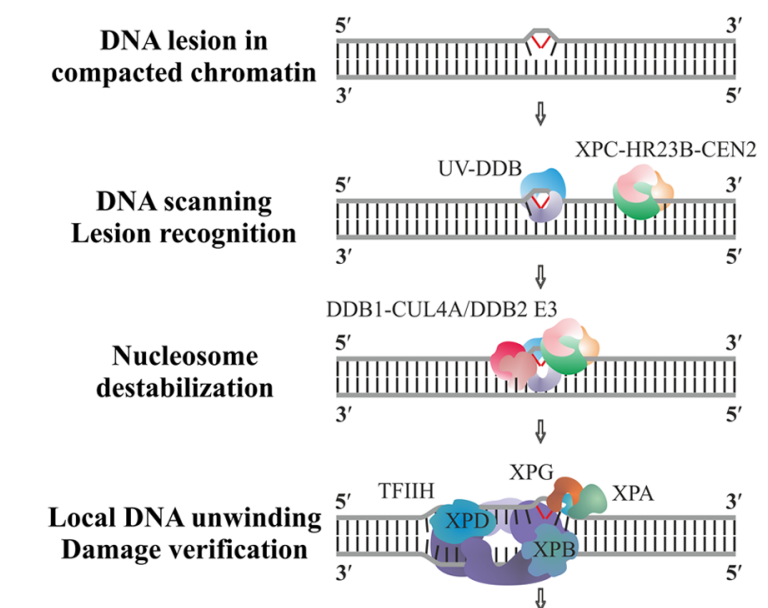

Repair synthesis

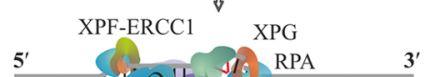

Endonucleolytic incision

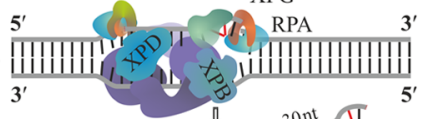

30nt AT

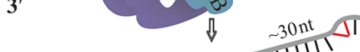

\section{s.}

NER

\section{Transcription-coupled Repair}

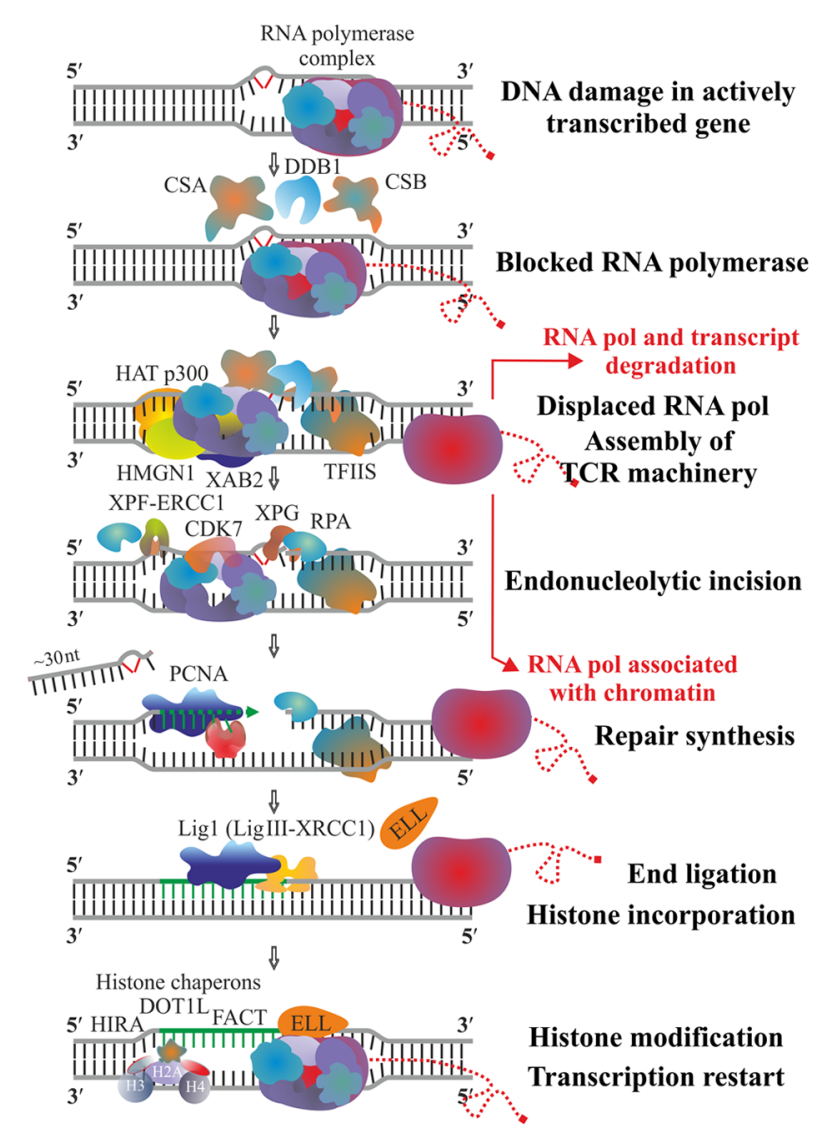

FIGURE 3 | Schematic representation of GGR and TCR in the eukaryotic cells. Two main concepts exist regarding the fate of stalled RP. According to the first model, after completion of repair, the transcription continues from the point it has been impaired without degradation of RNA Pol II and its nascent transcript; a key role in this step is attributed to the elongation factor ELL which is thought to help the backtracked RNA pol II to release from chromatin as well as to attract additional, yet unidentified factors allowing transcription restart (Mourgues et al., 2013). Another possibility is that the stalled polymerase and its growing transcript are released from DNA and further degraded; the lesion is removed and transcription starts by new RNA pol II complexes from the beginning of the gene on an intact damage-free template (Sarasin and Stary, 2007).

nicked $5^{\prime}$ and $3^{\prime}$ to the lesion by XPF/ERCC1 and XPG nucleases, respectively (Fuss and Tainer, 2011). It was shown in mammalian cells that binding of RPA protects the single-stranded DNA end from degradation, whereas PCNA (either ubiquitinated or not) coordinates the repair synthesis and ligation steps performed selectively by DNA polymerases $(\delta, \varepsilon$, or $\kappa)$ and DNA ligase I or DNA ligase III/XRCC1 in a cell-cycle dependent manner (Moser et al., 2007; Ogi et al., 2010). A global relaxation of the native chromatin is required in order to provide access of repair complexes to the DNA lesion, which in turn has to be restored after the final ligation step (Palomera-Sanchez and Zurita, 2011). Chromatin modifications such as histone acetylation and ubiquitination seem to be tightly associated with the processivity and completion of NER. Local nucleosome destabilization might be mediated by the complex DDB1-CUL4A/(DDB2) E3, which is responsible for the ubiquitination not only of the NER factors DDB2 and XPC, but also of the histones $\mathrm{H} 2 \mathrm{~A}, \mathrm{H} 3$, and $\mathrm{H} 4$
(Escargueil et al., 2008). Based on the latter observation, it has been suggested that the incorporated new histones may leave a kind of post-DNA repair imprints which could later affect epigenetic memory (Kamileri et al., 2012).

In higher eukaryotes the initial signal for TCR is emitted when the actively elongating RNA PolII complex stops on the transcribed strand due to the presence of damage. This is the reason why only this DNA strand is efficiently repaired whereas damage on the coding strand may persist for longer periods until being recognized by the GGR (Tornaletti, 2005). Key factors in TCR are CSA and CSB proteins (being components of different protein complexes) which bind the stalled RNAPolII. They, along with DDB1 initiate the assembly of other components of the TCR machinery such as HAT p300, HMGN1, XAB2, and TFIIS employed to displace the polymerase complex and modify chromatin, which results in exposure of the lesion to the common NER processing enzymes (Fousteri et al., 2006; 
Reed, 2011). In addition to the CDK7 kinase (essential during the processing step), novel TCR players have been identified as necessary for the continuation of gene transcription as soon as the template has been repaired. The elongation factor ELL is supposed to stimulate the dissociation of stalled RNA PolII from chromatin (Mourgues et al., 2013), whereas the proper chromatin environment, a prerequisite for successful post-repair restart of gene transcription, is ensured through modification of the newly assembled histones by specific histone chaperons such as HIRA, FACT, and DOT1L (Mandemaker et al., 2014).

Extensive studies in bacteria, yeast, and mammals have generated a large pool of data about the genetic control and biochemistry of NER and have also uncovered many structural and mechanical details of the lesion processing events. The last decade of intensified research in plant DNA repair field has revealed that most of the key NER genes are present in both model and crop plants, and notably many repair factors are identified as being components of similarly structured protein complexes. Moreover, in plants many NER genes have been interconnected to $\mathrm{HR}$ and photorepair and such a dynamic interplay of different DNA repair mechanisms may contribute to the adaptability and plasticity of plant genomes (Dubest et al., 2004; Molinier et al., 2008).

The AtCEN2 gene has been implicated in the early steps of plant GGR as part of the AtRAD4 (XPC) recognition complex. It was also shown to provide a link between NER and HR as an alternative mechanism for CPD repair in plants (Molinier et al., 2004; Liang et al., 2006). The role of the AtGTF2H2 protein in both transcription and NER has been inferred by its interaction with AtXPD helicase and further supported by its ability to act in the transcription and repair processes in yeast (Vonarx et al., 2006). In addition, AtGTF2H2, AtXPD, AtTFB1A, and AtTFB5 have been identified as being the Arabidopsis homologs to the human TFIIH factors $\mathrm{p} 44, \mathrm{XPD}, \mathrm{p} 62$, and TTDA, respectively. All of them were shown to be components of the plant TFIIH complex and a structural model for its core assembly has been developed based on protein interaction data (Grice et al., 2007). Two DDB1 homologs are present in the Arabidopsis genome $(D D B 1 A$ and $D D B 1 B)$, whereas in rice and tomato the $D D B 1$ is a single-copy gene. Genetic and molecular analyses have provided plenty of data about the involvement of CUL4-DDB1-DDB2 E3 ligase complex in plant GGR. The $C U L 4, D D B 1 A$, and $D D B 2$ insertion mutants in $A$. thaliana are hypersensitive to UV-C radiation and deficient in the dark repair of UV lesions (Molinier et al., 2008). In accordance with this, AtDDB1A overexpression improved the immediate response to the damaging UV light and was also necessary for the UVinduced regulation of the other $D D B 1 B$ and $D D B 2$ genes (Al Khateeb and Schroeder, 2009). The expression of the OsDDB gene was also shown to increase upon UV exposure but mainly in the meristematic rice tissues (Ishibashi et al., 2003). In addition to their involvement in NER, plant DDB factors have shown a broad range of protein interactions that appear critical for the normal development and physiology at different stages of the plant growth (Ganpudi and Schroeder, 2013). Mutations in AtXPD/UVH6, DDB1A, and DDB2 were found to influence both plant UV and heat response, and also cause defects in the floral development (Ly et al., 2013). In tomato, DDB1 has been linked to organogenesis, photomorphogenic response and even to the nutritional quality of the fruit, thus assigning a direct role of DNA repair-related genes and processes to the value of crops (Azari et al., 2010; Liu et al., 2012).

In plants the preferential removal of CPD and/or other DNA lesions from actively transcribed genes by NER pathway has not been a subject of intensive research, although repair heterogeneity has been proposed to occur in maize (Stapleton et al., 1997). In Arabidopsis, however, it has been recently shown that, in contrast to the low-rate repair observed at the whole genome level in the dark, the housekeeping RPII gene has been efficiently restored in a period of $24 \mathrm{~h}$ after UV-B irradiation. The more intriguing observation was that such repair was due to the enhanced CPD removal from the transcribed strand of the gene, thus providing a direct evidence for active TCR in the plant genome (Fidantsef and Britt, 2012). Consistent with these results AtCSA-like genes have been implicated in the regulation of TCR and UV damage response as part of the CUL4-DDB1 ${ }^{\text {CSAat } 1 A \text { and B }}$ complex in A. thaliana (Zhang et al., 2010a). The expression of the AtCSA-1 protein was found to be constitutively high in all plant tissues and therefore not upregulated by UV-B. However, its distribution in the nucleus showed a pattern of speckles in areas with high transcriptional activity, thus supporting involvement in TCR (Biedermann and Hellmann, 2010). Therefore, the selective operation of excision repair pathways at the level of actively transcribed genes seems really important for plants (i.e., more than previously appreciated) and it would be interesting to explore whether gene-specific repair might contribute to the UV tolerance in crops as well.

\section{Mismatch Repair}

The main biological role of the MMR system is to correct errors such as mismatches or nucleotides accidentally inserted/deleted during replication. In addition, $M M R$ participates in the correction of mispaired bases and loops in the recombination intermediates, rejection of excessive heteroduplexes, removal of exogenous DNA lesions such as psoralen-induced interstrand cross-links, oxidative DNA damage and UV photoproducts, as well as in nucleosome remodeling (Wu et al., 2005; Javaid et al., 2009; Lario et al., 2011; Honda et al., 2014). Hence, an efficient MMR helps the cell to increase the fidelity of DNA replication, to decrease the rate of mutations, to control the dynamics of short repetitive sequences, to maintain genome integrity, to conduct high-fidelity homologous and inhibit homeologous recombination, as well as to carry out proper meiosis (Spampinato et al., 2009). As an essential safeguard of genomic stability the MMR system is highly conserved in all living organisms, although some variations between the kingdoms were found to exist. The main prokaryotic MMR genes MutS and MutL have multiple homologs in the eukaryotes known as $M S H$ and $M L H$ gene families. Most of the eukaryotes contain at least six $M S H$ genes, whereas the seventh, $M S H 7$, is specific for plants (Culligan and Hays, 2000). MSH polypeptides combine in various heterodimeric complexes such as MSH2•MSH6 (MutS $\alpha$ ), MSH2•MSH3 (MutS $\beta$ ) or MSH4•MSH5, which are more or less specialized for certain DNA structures or DNA damage. 
They function in either replicative or recombination MMR, or in both. In general, the MSH heterodimers have lesion recognition and DNA binding activities, whereas the actual repair reactions initiate upon recruitment of the MLH heterodimer (Culligan et al., 2000). The endonuclease activity of MutL $\alpha$ (MLH1-PMS2) is particularly important for the strand-specific correctness of mismatch removal. Other proteins implicated in the downstream stages of MMR are Exo1, PCNA, RPA, RFC, and DNA polymerase $\delta$ (Modrich, 2006). In replicative MMR the main difference between bacteria and eukaryotes is in the mechanism used to differentiate between the inaccurately inserted and the normal nucleotide within the mismatch. In Escherichia coli the newly synthesized strand is easily distinguished because it initially lacks the methylation of specific DNA sequences. In eukaryotes the exact recognition mechanisms are not yet well understood, but it is now evident that they involve a tight interplay between replication and MMR (Jiricny, 2013). Indeed, data in yeast suggests that in the course of replication the MMR factors are temporarily coupled to the replication machinery which allows them to recognize repair signals elicited from the daughter strand shortly after replication (Hombauer et al., 2011). Up to now, eukaryotic MMR reactions have been fully reconstituted in vitro with both human and yeast MMR enzymes (Bowen et al., 2013), however, such studies are still to be performed in plants.

Similar to other eukaryotes, plants rely on the proper function of MMR factors during post-replicative and recombination MMR to preserve their genomic stability. In Arabidopsis, MSH2 deficiency inhibits homologous but increases homeologous recombination (Li et al., 2006) and enhances the microsatellite instability particularly in germline cells (Leonard et al., 2003), whereas MSH7 controls meiotic recombination (Lario et al., 2015). In cereals, the loss of MSH7 gene function impairs meiotic recombination and reduces plant fertility (Lloyd et al., 2007). Inactivation of AtMLHs leads to disruption of all MMRdependent processes such as meiosis, mitotic recombination, and damage removal (Dion et al., 2007). Plant MMR is not limited to the nucleus; the nuclear-encoded MSH1 protein also localizes in the extranuclear genomes of both dicots and monocots, where it influences different chloroplast and mitochondrial functions (Xu et al., 2012b). AtMSH polypeptides associate in vitro to form the known MSH2•MSH6 (AtMutS $\alpha$ ) and MSH2•MSH3 (AtMutS $\beta$ ) heterodimers, which exhibit binding efficiencies and mismatch substrate specificities similar to the other eukaryotic homologs, whereas the AtMutS $\gamma$ (MSH2•MSH7) protein complex shows specific substrate binding affinity which suggests more specialized functions (Wu et al., 2003). It was recently demonstrated that overexpression of plant MutS and MutL proteins in yeast cells significantly disturbs MMR function and consequently destabilizes the yeast genome. A specific role of AtMutS $\gamma$ in the recognition of mismatches generated at the sites of spontaneous or stress-induced DNA lesions has also been proposed (Galles and Spampinato, 2013; Gómez and Spampinato, 2013). Indeed, data have shown that plants deficient in AtMSH7, AtMSH2, or AtMSH6 genes when exposed to high UV-B levels, have higher CPD content, reduced CPD repair kinetics, as well as impaired cell cycle progression compared to the MMR proficient ones. In addition, wild type Arabidopsis and maize respond to UV-B irradiation by enhancing the expression levels of $\mathrm{MSH} 2$ and MSH6 genes, consistent with the role of the MMR system in the UV defense strategy of both model and crop plants (Lario et al., 2011, 2015).

There is an increasing demand to expand the current knowledge on the MMR system from model to crop species as such studies may have direct impact on the modern agriculture. Mutation-based breeding and introgressive hybridization have long been powerful tools in crop improvement and both these processes have been linked to the functionality of MMR in plants (Tam et al., 2009). It was suggested that inactivation of MMR may help induce mutagenesis with lower associated toxicity, as lower doses of mutagens would be sufficient to obtain desired traits in an MMR deficient background (Hoffman et al., 2004). MMR deficiency alone was sufficient to significantly increase the mutation rate in Arabidopsis without any mutagenic treatment, showing a mutation spectrum different from that achieved after EMS treatment. Therefore, in Arabidopsis an approach based on the reversible inhibition of MMR genes was successfully utilized to obtain plants with selectable phenotypes (Hoffman et al., 2004; Chao et al., 2005). The efforts to manipulate the MMR system are not confined to the Arabidopsis genome but have recently been employed in some crop species such as rice, tobacco, and tomato (Tam et al., 2011; Xu et al., 2012a; Van Marcke and Angenon, 2013). Various strategies have been applied such as RNAi-induced silencing and/or dominant negative suppression of MMR repair genes and all these techniques seem promising for the future agriculture to overcome the barriers between distantly related species or enhance mutation variability.

\section{Recombinational Repair and Non-homologous End Joining Detection and Signaling of DSB Occurrence}

The lack of plant genome stability may cause abnormalities in plant development and, in the case of crop plants, yield reduction. DSBs pose a major threat to genome stability because if not repaired before cell division they may lead to loss of substantial genetic material (Puchta, 2005; Feuerhahn and Egly, 2008; Charbonnel et al., 2010). DSBs have also been shown to cause programmed cell death in plants (Roy, 2014). In all eukaryotes, in the course of evolution, a complex system has been established, which includes DNA damage recognition and response pathway (DDR) and cell cycle checkpoint components. The DNA damage response mechanism and components of the cell cycle regulation coordinate DNA repair in the context of cell cycle phase. In order to initiate DSB repair, and to signal the occurrence of the DNA damage and recruit the repair proteins within the affected region of a nucleus, structural, and chemical modification of nucleosomes at the damaged site takes place, as shown in eukaryotes (van Attikum and Gasser, 2009). The primary signal transducers of DNA breakage are two phosphatidylinositol 3 kinase-like (PI3K) protein kinases: ATM and ATR. Both kinases initiate a phosphorylation-mediated signal transduction cascade that 
leads to cell-cycle arrest and repair of DSBs. The ATM and ATR kinases phosphorylate the histone variant H2AX in a large chromatin domain around the damage. This phosphorylation induces the accumulation of other damage-response factors and produces cytologically detectable foci (Amiard et al., 2011).

Arabidopsis atm mutants are sensitive to DSB-inducing factors, whereas the atr mutant plants are sensitive to replication stress (Garcia et al., 2003; Culligan et al., 2004, 2006). A role of these proteins in the DDR signaling in plants was validated by the fact that $\mathrm{H} 2 \mathrm{AX}$ phosphorylation in response to irradiationinduced DSBs is dependent on ATM (Friesner et al., 2005). In plants a signal of the presence of a DSB is transduced by the ATM kinase, whereas the signal communicating the presence of stretches of a single-strand DNA is transduced by the ATR kinase (Yoshiyama et al., 2013). Eukaryotic genomes encode histone variants, which differ from canonical histones in aminoacid sequence and are encoded by single-copy genes. These histone variants are associated with various genomic regions and play major roles in regulation of transcription, chromatin condensation, and in DNA damage response and DNA repair (Law and Cheung, 2013). As a consequence of the presence of a DSB, histone $\mathrm{H} 2 \mathrm{AX}$ is phosphorylated at the C-terminal part of the protein (histone variant $\gamma \mathrm{H} 2 \mathrm{AX}$ ) forming the $\gamma \mathrm{H} 2 \mathrm{AX}$ foci (van Attikum and Gasser, 2009). It was reported that the $\gamma \mathrm{H} 2 \mathrm{AX}$ foci constitute sites of recruitment of various DNA repair proteins (Paull et al., 2000). There is a correlation between the number of $\gamma \mathrm{H} 2 \mathrm{AX}$ foci and the number of DSBs, as well as between the rate of removal of the phosphorylated histones $\mathrm{H} 2 \mathrm{AX}$ and efficiency of DSB repair. In fact, measurement of $\gamma \mathrm{H} 2 \mathrm{AX}$ foci formation is considered several orders of magnitude more sensitive than other methods of DSB detection (Bonner, 2003; Löbrich et al., 2010). This approach to measurement of DSB repair was successfully applied in plant genomes (Friesner et al., 2005; Charbonnel et al., 2010), including crop species with relatively large genomes, such as barley (Stolarek et al., 2015a,b). Recently, in Arabidopsis, a land-plant-specific transcription factor SOG1 has been identified. It functions as a central regulator in DNA damage response and performs functions analogous to mammalian p53, being involved in the majority of plant response to DNA damage, such as transcriptional response, activation of cell cycle checkpoint and programmed death (Yoshiyama et al., 2014).

\section{Mechanisms of DSB Repair}

Upon DSB detection two different repair mechanisms may be initiated to repair the lesion - HR and non-homologous end joining. In DSB repair via HR the broken DNA ends are repaired based on the regions of sequence homology, whereas in NHEJ the sequence information does not play a significant role in re-joining of DSBs (Puchta, 2005). The latter mechanism does not require homologous template sequence and is therefore errorprone (Charbonnel et al., 2010). HR can also be error prone if not restricted to the identical locus on a sister chromatid. The principle mechanisms and basic factors in HR-mediated DSB repair and NHEJ are conserved in eukaryotes (Puchta and Fauser, 2014). Studies aimed at characterization of DNA repair processes in plants have been conducted mainly in Arabidopsis. Our previous studies indicated that, based on high conservation level of these processes across various evolutionary groups of organisms, gene, and protein sequences related with DNA repair may be deployed as queries for browsing databases to identify homologous sequences in other species, including crop plants, in which these mechanisms are poorly understood (Gruszka et al., 2012). Application of various approaches in plant systems and sequencing of re-joined sites allowed identification of specific features of DSB repair in plants: end joining is usually associated with various sequence rearrangements (insertions, deletions) ranging up to $1 \mathrm{~kb}$, and rejoining frequently takes place at sites of short repeats. Moreover, the sequences inserted at the re-joined site may be derived from other locations in a genome consequently NHEJ in plants appears more error-prone than in other organisms (Gorbunova and Levy, 1999; Puchta, 2005). Analysis of DSB joining in two plant species varying significantly in their genome size - Arabidopsis and tobacco - indicated that the pattern of sequence alterations at the junction sites varies between the plant species and that large deletions at the junction sites are more frequent in smaller genome of Arabidopsis (Kirik et al., 2000; Lloyd et al., 2012). This indicates that error-prone NHEJ may contribute significantly to the evolution of plant genome size (Puchta, 2005). It is now known that high-fidelity DSB repair via HR is less frequent in plant genomes than NHEJ (Puchta and Fauser, 2014). On the other hand, in plant genomes, especially the large ones, with high content of repeated sequences, recombination between two non-allelic sequences may lead to crossovers and genome rearrangements and in this situation NHEJ proves safer than HR. The generally used classification of HR-mediated repair versus NHEJ may be oversimplified because, especially in plants, both mechanisms act together, and many rearrangements observed in plant genomes may be explained by a combination of these pathways. Although DNA repair in lower organisms usually is more accurate, accuracy of DNA repair cannot be simply correlated with genome size or amount of repetitive DNA (Gorbunova and Levy, 1999). Mechanisms of DSB emergence and induction as well as various damage recognition and repair pathways are presented in Figure 4.

\section{Non-homologous end joining}

Upon detection of a DSB and recruitment of the abovementioned signaling components several repair pathways may be activated. According to the current classification the NHEJ pathway is divided into several sub-pathways, including canonical or cNHEJ and the recently discovered aNHEJ subpathway (Mladenov and Iliakis, 2011).

The cNHEJ mechanism is highly conserved among both proand eukaryotic organisms. It is involved in the repair of DSBs that are produced by both physical and chemical factors, but also as a result of $\mathrm{V}(\mathrm{D}) \mathrm{J}$ recombination in animals, and T-DNA integration into a genome during transformation (Charbonnel et al., 2010; Lieber, 2010; Charbonnel et al., 2011; Boboila et al., 2012; Park et al., 2015). The process is initiated by damage recognition mediated by the heterodimer Ku70/Ku80 forming a ring structure, which binds both DNA ends, brings them together and prevents their degradation (Walker et al., 2001; 


\section{Endo- and exogenous DSB-inducing factors:}

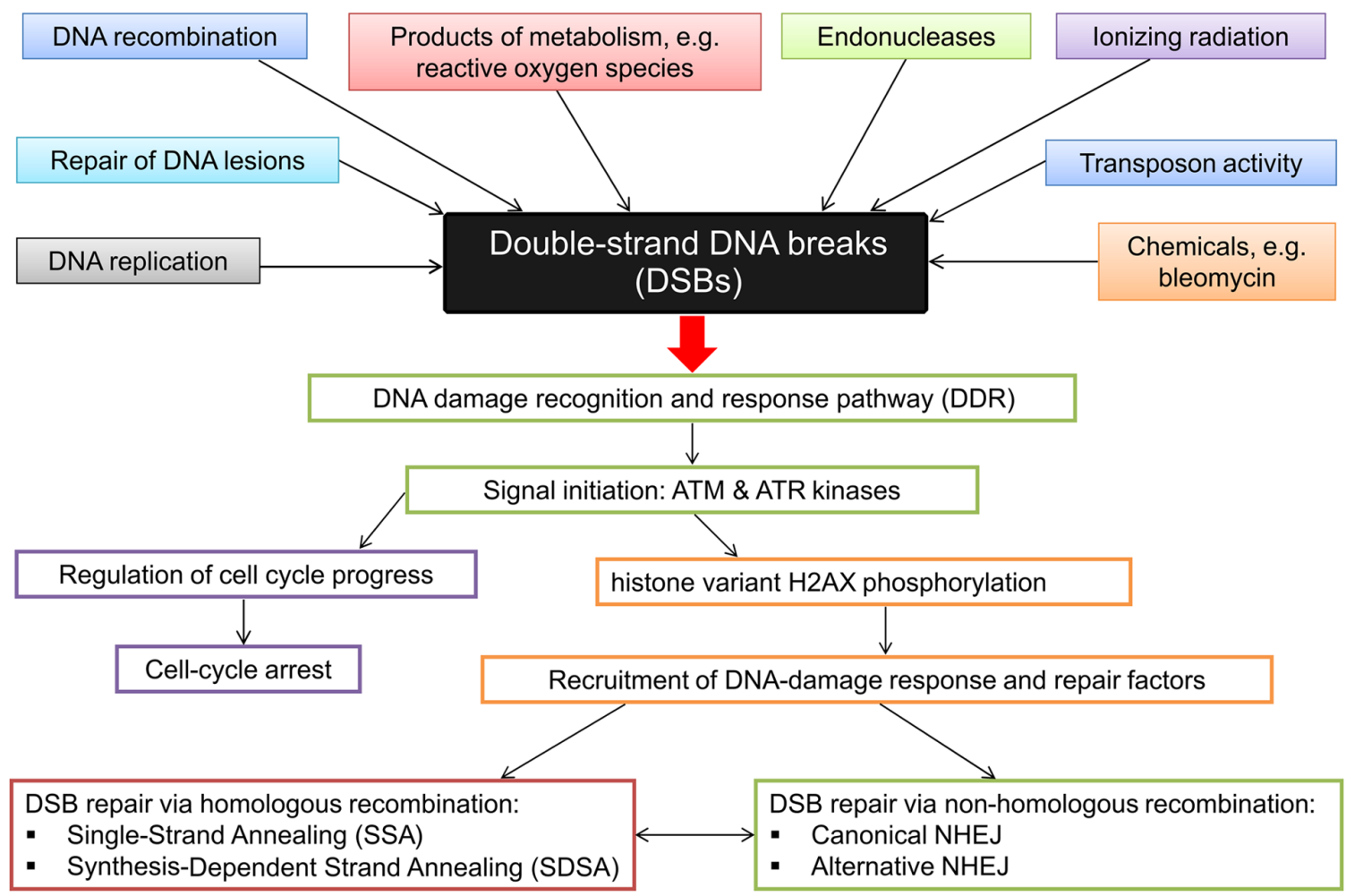

FIGURE 4 | Diagrammatic representation of the DSB inducing factors and the various damage recognition and repair pathways.

Mannuss et al., 2012). Therefore, cNHEJ often causes a minor change in genetic information (Puchta and Fauser, 2014). The step mediated by the $\mathrm{Ku} 70 / \mathrm{Ku} 80$ heterodimer is followed by the recruitment of DNA-PKcs kinase, which promotes or restrains the access to damaged DNA ends. However, the DNA-PKcs kinase has not been identified in plants (Nishizawa-Yokoi et al., 2012). At the site of the lesion the DNA ends are processed, as required, by several proteins to restore the correct phospho- and hydroxyl-groups at both the $5^{\prime}$ and $3^{\prime}$ DNA ends, respectively. The cNHEJ pathway is terminated by DNA ligation, which is mediated by various proteins, such as the LigIV/XRCC4, XLF, PARP3 [Poly(ADP-ribose) polymerase 3] and the APLF protein (Neal and Meek, 2011; Rulten et al., 2011).

Key players participating in cNHEJ, such as Ku70, Ku80, XRCC4, and ligase IV have been identified in Arabidopsis. Mutations in the $K u 70, K u 80$, and $\operatorname{LigIV}$ genes lead to increased sensitivity to DSB-inducing factors (West et al., 2000; Tamura et al., 2002; West et al., 2002). Inactivation of the Ku80 protein in Arabidopsis considerably reduces the efficiency of cNHEJ. However, surprisingly Arabidopsis ku70, ku80, and ligIV mutants do not show growth defects or increased inviability (Bleuyard et al., 2006). Arabidopsis Ku70 and Ku80 proteins were shown to bind double-stranded DNA (non-telomeric and telomeric sequences), but not single-stranded DNA. Both proteins possess ATPase and ATP-dependent DNA helicase activities. Expression of these genes is increased in response to DSB-inducing factors such as BLM and MMS (Tamura et al., 2002). Orthologs of XLF have not been identified in plants. Three genes encoding proteins similar to Artemis were identified in the Arabidopsis genome, but their role in cNHEJ was not validated (Charbonnel et al., 2010). The key mediator of the cNHEJ process - the Ku70/Ku80 heterodimer is also suggested to function as a repressor of HR within telomeric sequences, which may lead to the shortening of telomeres. In Arabidopsis the involvement of the Ku80 protein in telomere length regulation was confirmed and the atku80 mutant has longer telomeres than wild type (Gallego et al., 2003; Fattah et al., 2010). The function of the Ku70/Ku80 heterodimer has been validated in rice (Nishizawa-Yokoi et al., 2012) and wheat (Gu et al., 2014). Recently, barley mutants carrying mutations in the Ku 80 gene were identified. These mutants accumulated BLMinduced DSBs to a much greater extent than the parent cultivar. The study also demonstrated a significant role of the $\mathrm{HvKu} 80$ gene in the regulation of telomere length in barley (Stolarek et al., 2015b).

In the less well-characterized aNHEJ process, $3^{\prime}$ resection of the broken DNA ends occurs. Annealing of the two single strands leads to junction formation at the sites where few complementary nucleotides are present. The end flaps are usually trimmed, re-joining occurs and the microhomologies get exposed at the junction site. As a result of DSBs resection, the aNHEJ process usually leads to deletions at the junction site (Puchta and Fauser, 2014). It was reported that the PARP1 and XRCC1 
proteins are involved in this process and are conserved both in mammals and plants (Charbonnel et al., 2011; Jia et al., 2013). Very often genetic information at the junction site is lost, therefore the aNHEJ process is considered as highly mutagenic way of DSB repair (Puchta and Fauser, 2014). It was also demonstrated that both NHEJ sub-pathways compete for DSB repair. In the Arabidopsis mutant ku80 occurrence of the errorprone re-joining (aNHEJ) was increased by 2.6-fold and higher frequency of end degradation was observed (Osakabe et al., 2010). It was reported that an additional NHEJ pathway may be responsible for repair of some DSBs in the absence of cNHEJ and aNHEJ (Charbonnel et al., 2011). The function of the PARP genes in Arabidopsis is still far from being fully elucidated, however, it was recently suggested based on high expression level of this gene in seeds, that it may play a crucial role in DNA damage response at this developmental stage. Upon seed imbibition ROS are produced, which may result in DNA damage. Under these conditions DNA repair is critical to maintain the genome integrity of developing embryo (Balestrazzi et al., 2011; Boltz et al., 2014). Based on the information from model species Arabidopsis and rice, recently the barley PARP3 homolog has been identified. Expression of the HvPARP3 gene is enhanced by the DSB-inducing chemical BLM. This result indicates that $H v P A R P 3$ functions as a component of DNA damage-response system. Mutational analysis of the gene led to the identification of a series of alleles. Mutation of the amino-acid residue located in a highly conserved domain evoked a significant increase in the number of DSBs produced after the mutagenic treatment, which was measured with various approaches (Stolarek et al., 2015a).

\section{Homologous recombination}

In somatic cells of plants $\mathrm{HR}$ is a minor DSB repair pathway functioning mainly during the $S$ and $G_{2}$ phases of the cell cycle. The two most prominent HR-dependent pathways of DSB repair in plant somatic cells are SSA and SDSA (Puchta, 2005). The most common intermediate step of the DSB repair process is resection of DNA ends and exposure of single-stranded $3^{\prime}$ overhangs. This was proposed as the first step for the majority of DSB repair pathways in plants and seems to be mediated by the MRN complex. Plant homologs of MRE11, RAD50, and NBS1, which form the MRN complex, have been identified (Hartung and Puchta, 1999; Gallego and White, 2001; Akutsu et al., 2007). In Arabidopsis the functions of two components of this complex - AtMre11 and AtRAD50 were validated and co-immunoprecipitation assays indicated that these two proteins form a complex (Gallego et al., 2001; Bundock and Hooykaas, 2002; Daoudal-Cotterell et al., 2002). The MRN complex is also required for $\gamma \mathrm{H} 2 \mathrm{AX}$ phosphorylation by the ATM and ATR kinases in response to DNA damage (Amiard et al., 2010). It is suggested that in Arabidopsis the MRN (Mre11Rad50-Nbs1) complex may also be recruited to DSBs by the $\mathrm{Ku} 70 / \mathrm{Ku} 80$ heterodimer during the NHEJ pathway (Tamura et al., 2002). Characterization of the atmre11 and atrad50 mutants indicated conservation in the functions in recombination and DSB repair of the Arabidopsis MRN complex (Bleuyard et al., 2006). Inactivation of the AtMre 11 and AtRAD50 genes conferred a phenotype of hypersensitivity to DSB-inducing factors, but the mutant plants remained viable (Gallego et al., 2001; Bundock and Hooykaas, 2002). However, sterility observed in these mutants suggests conservation of the role of the MRN complex in HR during meiosis (Gallego et al., 2001; Puizina et al., 2004). Cytological analyses of meiotic cells indicated that the sterility is caused by DNA fragmentation during meiotic prophase (Puizina et al., 2004). Another factor important for the initiation of HR is the RPA, which is a eukaryotic heterotrimeric protein complex that binds single-stranded DNA. In plants, multiple genes encode the three RPA subunits (RPA1, RPA2, and RPA3; Ishibashi et al., 2006; Shultz et al., 2007; Atwood et al., 2014; Eschbach and Kobbe, 2014). The RPA complex plays essential roles in various DNA metabolic pathways, including DNA replication, meiotic recombination, and repair. This complex participates also in the activation of the cellular response to DNA damage (Aklilu et al., 2014). Moreover, in Arabidopsis, one of the subunits (RPA1) takes part in the NHEJ process and negatively regulates the telomere length (Takashi et al., 2009).

According to the SSA model the two single-stranded 3 'overhangs may anneal at the site of microhomology (Gorbunova and Levy, 1999). In Arabidopsis and other model organisms this process is mediated by the Rad52 protein (Samach et al., 2011). The SSA process may only occur when the DSB is located between two homologous/complementary sequences. If the resulting DNA molecule contains non-complementary overhangs they are removed, and the remaining single-stranded gaps are filled by DNA polymerase and the repair is completed by ligation by DNA ligase I. The SSA pathway is a nonconservative mechanism, as it usually leads to deletions of sequences which were originally located between repeated sequences of microhomology (Puchta and Fauser, 2014). The SSA mechanism seems to be of great importance for molecular evolution of genomic regions with tandem duplications. In these regions up to one-third of DSBs is repaired with the use of the SSA pathway (Siebert and Puchta, 2002). The SSA mechanism leading to deletion of sequences located between direct repeats is particularly efficient. It may explain the abundance of single LTRs as remnants of retrotransposons in cereal genomes (Puchta, 2005).

The other DSB repair model - SDSA - is based on invasion of a homologous, double-stranded template molecule with a single-stranded $3^{\prime}$ overhang, which is then extended during DNA synthesis. The single-stranded $3^{\prime}$ overhang invasion into the template molecule is most likely mediated by the RAD51 protein and its paralogs (Bleuyard et al., 2005; Osakabe et al., 2005). In the Arabidopsis genome AtRAD51 is a single-copy gene, and its transcription is increased after gamma-irradiation (Doutriaux et al., 1998; Bleuyard et al., 2006). It was reported that the atrad51 mutants are viable, even though the mutants showed a severe sterility phenotype due to defects in synaptonemal complex assembly and chromosomal instability during meiosis ( $\mathrm{Li}$ et al., 2004). Most probably the formation of the RAD51/ssDNA nucleofilament is also mediated by Arabidopsis orthologs of the BRCA2 protein, which interacts directly with AtRAD51. Similar to the atrad51 mutants, Arabidopsis RNAi lines in which the AtBRCA2 gene was knocked-down showed partial sterility caused by chromosomal instability during meiosis (Siaud et al., 
2004). Contrary to the SSA pathway, the SDSA mechanism is conservative, as homology from the donor sequence (template DNA molecule) is copied into the DSB without any loss of DNA sequence (Puchta and Fauser, 2014). The SDSA pathway was reported to be five to ten times less efficient in DSB repair than the SSA mechanism under comparable conditions (Orel et al., 2003). The mechanism of SDSA explains the frequent events of gene conversion or insertion of filler DNA at the rejoining site. During this process the single $3^{\prime}$ end invades a homologous double-stranded, template DNA molecule, forming a D-loop structure (Puchta and Fauser, 2014). It is now known that both the $3^{\prime}$ single-stranded overhangs may act independently in search for a template molecule, which is to be invaded. Therefore, in the SDSA mechanism both homologous and nonhomologous templates may be invaded (Gorbunova and Levy, 1999). The SDSA mechanism is considered a conservative mode of DSB repair and usually results in gene conversions, however, without Holliday junction formation and crossover events. This mechanism seems to play a significant role in molecular evolution of tandemly arranged gene families (Puchta, 2005). During the DNA synthesis interaction between the template and the extended strand is weak, and therefore abortion of synthesis and template switch may occur. Multiple template switches result in complex 'patchwork' DNA inserts at the re-joining site (Gorbunova and Levy, 1999). The SDSA mechanism may constitute the most versatile model of genomic DSB repair in somatic plants cells, as it is based on one-sided initiation and may combine both HR and NHEJ events. If the $3^{\prime}$ end of the invading strand is elongated up to the homology with the second $3^{\prime}$ end of the DSB (available due to resection) both single strands may anneal (microhomology-based second end capture). However, if the $3^{\prime}$ end of the invading, elongated strand is not complementary to the other $3^{\prime}$ end of the DSB the break is ultimately repaired via NHEJ. In contrast to the SSA mechanism, no sequence is lost as a result of the SDSA process, however, the information content may be altered (Puchta, 2005; Puchta and Fauser, 2014). Normally, sequences in close proximity on the same chromosome or sister chromatid are used as templates for SDSA, and ectopic or allelic homologies are rarely used in DSB repair (Gisler et al., 2002).

As suggested by the different mechanisms of the SSA and SDSA pathways, groups of DNA repair-related proteins mediating both processes are quite different. The strand exchange results in formation of an intermediate of the SDSA process, therefore the RecA homologs RAD51 and XRCC3 were identified as mediators of this process in Arabidopsis. Additionally, AtRAD54 being an ATPase and belonging to the SWI2/SNF2 family of molecular remodelers of DNA structure, is also essential for the SDSA process (Roth et al., 2012). The AtRECQ4A and AtFANCM DNA helicases, and nucleases, such as AtMUS81, play a role in SDSA, but only a minor in the SSA pathway (Mannuss et al., 2010). In the case of the SSA pathway the RAD1/RAD10 heterodimer, which functions as a structure-specific flap-like endonuclease, is involved in trimming of the complementary strands before ligation (Dubest et al., 2002). No other factors, which would be essential for the SSA mechanisms have been identified yet (Puchta and Fauser, 2014).
The classical HR model of DSB repair involves formation of a Holliday junction, and resolution of this structure resulting in gene conversion and crossover. In this mechanism both strands of the template molecule are simultaneously used during extension of both single-stranded $3^{\prime}$ overhangs (Gorbunova and Levy, 1999). However, it should be noted, that homology to only one end of the DSB is sufficient for initiation of HR, and DSB repair in plant cells may be initiated by a one-sided interaction event (Puchta, 2005). It is now suggested that both DSB repair via HR and Holliday junction formation and SDSA mechanism may be utilized in plant cells. However, depending on the context - Holliday junctions are formed predominantly during meiosis when fidelity of repair is assured by pairing of homologous chromosomes (Keeney, 2001), while the SDSA mechanism functions mainly in somatic cells (Puchta, 2005).

Both the SSA and SDSA pathways may be part of homologous and non-HR. However, comparison of efficiencies of both pathways indicated that SSA mechanism is about five times more efficient than the SDSA mechanism. Therefore, the SSA mechanism may be the most prominent homology-based way of DSB repair in higher eukaryotes, in general. However, an accumulating body of evidence derived from various approaches and experiments indicates the most efficient way of DSB repair in plant somatic cells is NHEJ. Nevertheless, if homologous sequences are available during the repair process, in one-third of the cases DSBs are repaired via the SSA pathway, and about six percent of the DSB repair events proceed via the SDSA model (Puchta, 2005).

\section{SITE-SPECIFIC DSB INDUCTION AS A TOOL FOR TARGETED MUTAGENESIS}

Rare cutting endonucleases have been applied as tools for induction of DSBs and the analysis of many aspects of DSB repair in plant genomes (Mannuss et al., 2010; Roth et al., 2012; Wei et al., 2012). Combining knowledge about mechanisms of DSB repair, their consequences and application of sequence-specific endonucleases led to development of site-specific DSB induction as a tool for targeted mutagenesis. Alterations in a genome sequence are introduced by DSB formation, which induces natural repair mechanism. Synthetic nucleases may be applied to induce DSBs which lead to mutations through erroneous NHEJmediated DSB repair. Site-specific DSB induction may also be a starting point for transgene integration into a genome via NHEJ or HR pathway (Voytas, 2013; Puchta and Fauser, 2014). It was shown that ZFNs may be used for sequence-specific mutation induction in the Arabidopsis genome via NHEJ (Lloyd et al., 2005) and as an efficient approach for knockout of Arabidopsis genes via the same DSB repair mechanism (Osakabe et al., 2010; Zhang et al., 2010b). It was also reported that ZFNs may be applied for gene-targeted mutagenesis in tobacco and maize by DSB-induced HR (Shukla et al., 2009; Townsend et al., 2009). ZFNs became a very efficient tool for genome editing in plants and the list of plant genomes that may be modified in the site-specific DSB-dependent manner is constantly growing (Weinthal et al., 2010; Puchta and Fauser, 2014). 
However, new alternatives emerged recently. TALENs are one of these very effective approaches to genome engineering (de Lange et al., 2014). Recent studies have shown a huge potential application of TALENs for targeted plant genome mutagenesis (Christian et al., 2010; Mahfouz et al., 2011; Shan et al., 2013a; Wendt et al., 2013). An example of a trait obtained through TALEN-based targeted mutagenesis is a soybean variety that produces oil with elevated levels of the monounsaturated fat - oleic acid. The TALEN-based approach was deployed to mutate the FAD2-1A and FAD2-1B genes encoding fatty acid desaturases (Haun et al., 2014). Another system - CRISPR/Cas and associated endonuclease is an alternative tool to induce sequence-specific DSBs in model and crop plant genomes (Feng et al., 2013; Jiang et al., 2013; Li et al., 2013; Mao et al., 2013; Miao et al., 2013; Nekrasov et al., 2013; Shan et al., 2013b; Xie and Yang, 2013). In Arabidopsis protoplasts the frequency of NHEJbased targeted mutagenesis reached $5.6 \%$, whereas in Nicotiana benthamiana the frequency was up to $38.5 \%$ (Li et al., 2013). Efficient NHEJ-mediated targeted mutagenesis was also observed in rice protoplasts, however, with varied frequencies (14.5-38\%), and in wheat protoplasts, at a frequency of $28.5 \%$ (Shan et al., 2013 b). It was demonstrated in several studies that DSB induction by Cas endonucleases is useful for targeted mutagenesis, but also for HR-related techniques of plant genome engineering (Feng et al., 2013; Mao et al., 2013; Miao et al., 2013). Experiments aimed at DSB-induced genetic engineering are currently being developed for a number of plant genomes, and the CRISPR/Cas system has proved to be efficient in a number of model and crop plants; however, it should be kept in mind that efficient transformation and regeneration of transgenic material in some cereal crop species, like barley is still a challenge (Puchta and Fauser, 2014). Mechanisms of DNA repair have been studied for many years in basic research, and currently our understanding of these processes, and DSB repair in particular, becomes a crucial element of development of advanced tools for precise genome modification procedures and targeted mutagenesis.

\section{SMALL RNAs IN PLANT DNA DAMAGE AND REPAIR}

RNA interference is a cellular mechanism for control of gene transcription via small RNAs (siRNAs, miRNAs, ta-siRNAs, etc.) which promote the degradation of their target mRNAs thus leading to gene silencing. Small RNAs are an excellent tool for suppression of gene expression in order to study the genetic control of various cellular pathways. More importantly, they have an enormous practical application in both human health and agricultural practice. Regarding the latter, in plants, small RNAs offer the possibility to manipulate and engineer plant genome and have been widely utilized to obtain desired traits in crop plants (Saurabh et al., 2014).

Over the last decade, RNAi-based technology has become a major breakthrough in DNA repair research. Its application allowed elucidation of the particular role the individual proteins and protein complexes play in different aspects of DNA damage control and repair. In mammalian cells, such studies have become a routine practice in many laboratories. In plants, experimentally generated transgenic RNAi lines have been extremely useful to reveal the interplay between $\mathrm{HR}$ and NER pathways in Arabidopsis (Molinier et al., 2004), to examine the link between chromatin modifications and UV-B damage response in maize and Arabidopsis (Casati et al., 2008; Fina and Casati, 2015), to identify a novel Lig1-dependent DSB repair pathway in Arabidopsis (Waterworth et al., 2009), etc. Nevertheless, the employment of RNAi in the studies on DNA repair in crop species remains to be expanded in the future.

In addition to the key role the different types of naturally occurring small RNAs play in various molecular processes in plants, such as stress defense, epigenetic control, and transposon suppression, it was recently shown that they might be involved, directly or indirectly, in DNA damage response and DNA recombination and repair. A computational approach utilizing microarray gene expression data from Arabidopsis identified a number of miRNA genes, which are upregulated in plants exposed to UV-B radiation, and determined that their targets code for different transcription factors or belong to the auxin signaling pathways (Zhou et al., 2007). It was shown that Arabidopsis mutants, deficient in the DCL enzymes or RNA dependent RPs, display differential response to MMS varying from higher sensitivity to higher tolerance compared to the wild type. In addition, $d c l 2$ and $d c l 3$ mutants have decreased ability to repair UV-C generated DNA lesions, suggesting a link between siRNA biogenesis and DNA repair (Yao et al., 2010). It was also shown that the DCL enzymes are involved in DSB repair in both Arabidopsis and human cells, possibly via production of small RNAs from sequences surrounding the DSB. It was proposed that these diRNAs mediate DSB repair and their recruitment occurs through the AGO2 protein, which is a central factor of the RISC complex (Wei et al., 2012). These findings were extended in mammalian cells and revealed that diRNAs and AGO2 are essential for the initiation of HR, where they facilitate RAD51 accumulation onto DNA (Gao et al., 2014). On the other hand, further experiments in Arabidopsis showed that ago mutant plants were not impaired in the meiotic recombination, however, the sensitivity of ago 2 as well as of ago 9 mutants to gamma radiation and mitomycin $\mathrm{C}$ was confirmed (Oliver et al., 2014). Generally, it might be expected that the new developments in RNAi-based technologies, combined with the knowledge on the mechanisms by which plants exploit small RNAs to activate and control their DNA damage tolerance and repair mechanisms under adverse conditions, would advance significantly the molecular plant breeding methods aimed at improving crop quality and production.

\section{IMPLICATION OF DNA DAMAGE AND REPAIR IN BIOTIC STRESS TOLERANCE IN PLANTS}

In field conditions plants are not exposed to a single type of stress, but rather have to accommodate quickly to a combination of abiotic and biotic stress factors. In this respect, the recent research points to complex interconnections between the formation of 
DNA damage, activation of DNA repair pathways and plant defense response to pathogen attack. DSBs were detected in the Arabidopsis genome upon various types of pathogenic infection. The formation of these infection-induced DSBs was independent of the ROS production as a part of the host response. Moreover, it was found that the activation of pathogenic defense pathways also contributed to the maintenance of genomic integrity (Song and Bent, 2014). A number of studies have shown that HR was strongly enhanced in plants exposed to biotic stress and, more intriguingly, HR frequency was kept higher in their progeny as well (Molinier et al., 2006), accompanied with locus specific changes in DNA methylation pattern (Boyko and Kovalchuk, 2011). In addition, repair proteins engaged in $H R$ have been implicated in the transcriptional control of genes involved in plant immune response (Song et al., 2011). On the other hand, it was demonstrated that the presence of UV lesions enhanced plant tolerance to pathogenic infection, but an inverse correlation was found between plant's ability to repair those lesions and its pathogenic resistance (Kunz et al., 2008). It appears that the occurrence of certain levels of DNA lesions in the plant genome may be beneficial for plants to promote tolerance to pathogenic infection by keeping their defense pathways active. Overall, accumulating evidence shows that plants depend on DNA repair not only to overcome both abiotic and biotic stresses, but also to ensure better stress adaptation in further generations. Thus, in the long-term, revealing the mechanisms which govern such interactions may help to improve crop plants to better adjust to the dynamic environment.

\section{DNA REPAIR IN THE CONTEXT OF MUTATION INDUCTION AND CROP IMPROVEMENT}

Although DNA damage is often considered regarding its mutagenic effect, the persistence of damaged bases also has a significant growth-inhibitory influence. Because the genetic variation created in part through mutation and recombination are prerequisites of both natural and artificial selection, the understanding of mechanisms of genetic change is relevant for both - our knowledge of evolution and for genetic manipulation of crop plants. Techniques of mutagenesis are a very efficient tool to develop necessary germplasm collections in model and crop species, facilitating discovery of desired loci and alleles. Identification of genes participating in these processes may shed light on molecular mechanisms of DNA repair. Induction of mutations within genes involved in DNA repair or lesiontolerance pathway may alter the efficiency of these processes and, as a consequence, render the mutagenesis more effective.

Recently performed studies conducted with the use of bioinformatics tools enabled outlining the list of genes participating in various pathways of DNA damage repair in A. thaliana (Gruszka et al., 2012). However, information regarding mechanisms of DNA damage repair in crop plants is very limited. Understanding of the molecular basis of DNA repair and genome maintenance may allow more directed and fine-tuned mutation-induction techniques. It is important to take into account the global economic impact of the development of induced mutant-derived crop species (Ahloowalia et al., 2004).

During the last seven decades, worldwide more than 3200 varieties have been released, that were derived as direct mutants or from their progenies (Pathirana, 2011; IAEA Mutant Database $\left.{ }^{1}\right)$. Direct development of mutant varieties has been achieved mainly through application of radiationbased mutagenesis, mostly gamma and X-rays. Application of IR allowed development of important traits in crop species: resistance to bacterial leaf blight and blast in rice (Xiao et al., 2008), resistance to yellow mosaic virus in barley (Tanaka et al., 2010), resistance to potato virus $\mathrm{Y}$ in tobacco (Hamada et al., 1999), and resistance to black sigatoka in banana (ReyesBorja et al., 2007). In a review by Pathirana (2011) a list of disease-resistant mutants developed directly through gamma irradiation in various crop species is presented. Mutant-derived varieties have been released in 175 plant species, including many important crops, such as rice, wheat, barley, cotton, rapeseed, sunflower, sesame, grapefruit, and banana. Many of these varieties have significant economic importance. For example, according to a report of the Japanese Science and Technology Agency, eighteen mutant-derived varieties of rice contributed US\$ 937 million annually to the Japanese agriculture (Ahloowalia et al., 2004; Pathirana, 2011). The gamma ray-induced rice cultivar 'Zhefu 802' with a shorter growing season, cold tolerance and high yield potential under low-input conditions was the most widely cultivated variety in China for almost a decade. During this period its overall planted area reached 10.6 million ha (Kharkwal and Shu, 2009). The development of mutantderived varieties and research on mutation techniques and molecular mechanisms of DNA damage and repair have long been supported by the Food and Agriculture Organization (FAO) and International Atomic Energy Agency (IAEA). This effort is particularly important in light of the rapidly growing world population and the need to improve and increase food production in the next few decades. However, in many countries, especially in Europe, issues concerning introduction of genetically modified crop varieties persist. Mutation-derived varieties meet criteria of non-GMO plants and may therefore be broadly applied in plant breeding.

\section{AUTHOR CONTRIBUTIONS}

VM and DG conceived a plan and draft of the manuscript, wrote the manuscript and gave final approval for submission.

\section{FUNDING AND ACKNOWLEDGMENTS}

The authors gratefully acknowledge financial support of research conducted in their laboratories by the Food and Agriculture Organization (FAO) and International Atomic Energy Agency (IAEA) within the frames of CRP D24013 "Isolation and Characterization of Genes Involved in Mutagenesis of Crop

${ }^{1} \mathrm{http}: / /$ mvd.iaea.org 
Plants," grants No 15481 R0-R3 (VM) and 15657 R0-R3 (DG). DG acknowledges financial support from the Polish Ministry of Science and Higher Education (Grant Nos. 687/WIAEA/2010/0, 773/W-IAEA/2010/0, 2214/FAO/IAEA/2011/0, and 2725/FAO/IAEA/2013/0). The authors would like to thank Prof. Anne B. Britt (Department of Plant Biology, College of Biological Sciences, UC Davis) for critical review of the manuscript.

\section{ABBREVIATIONS}

General abbreviations: AP, Apurinic/apyrimidinic; BER, Base excision repair; BLM, Bleomycin; Cas, CRISPR-associated; CPD, Cyclobutane pyrimidine dimer; CRISPR, Clustered Regularly Interspaced Short Palindromic Repeats; DASH, Drosophila, Arabidopsis, Synechocystis, Human; diRNA, DSB-induced small RNA; DSB, Double-strand break; EMS, Ethyl methanesulfonate; $\mathrm{HR}$, Homologous recombination; IR, Ionizing radiation; LTRs, Long terminal repeats; miRNA, MicroRNA; MMR, Mismatch repair; MMS, Methyl methanesulfonate; NER, Nucleotide excision repair; NHEJ, Non-homologous end-joining; aNHEJ, Alternative DNA-PKcs-independent NHEJ; cNHEJ, Classical DNA-PKcs-dependent NHEJ; 6-4 PP, Pyrimidine6-4pyrimidone photoproduct; REs, Restriction endonucleases; RNAi, RNA interference; RISC, RNA-induced silencing complex; ROS, Reactive oxygen species; SDSA, Synthesis-dependent strand annealing; SSA, Single-strand annealing; SSB, Single-strand break; siRNA, Small interfering RNA; ta-siRNA, Transacting siRNA; TALENs, Transcription Activator-Like Effector Nucleases; UV, Ultraviolet radiation; V(D)J recombination, Antigen receptor gene rearrangement of variable (V), diversity (D) and joining (J) gene segments; ZFNs, Zinc Finger Nucleases.

Gene and protein abbreviations: AGT, Alkylguanine DNA alkyltransferase; APLF, Aprataxin and PNK-like Factor; AGO, Argonaute; ARP, Apurinic endonuclease-redox protein; ASF, Anti-silencing function1; ATM, Ataxia-Telangiectasia mutated; ATR, ATM and RAD3-related; BRCA2, Breast Cancer2; CDK7, Cyclin-dependent kinase7; CEN2, Centrin2; COP1, Constitutive photomorphogenesis protein 1; CSA/B, Cockayne syndrome A/B; CSA-like, Cockayne syndrome-like; CUL4, Cullin4; DCL, DICER-like; DDB1/2, Damaged DNA binding1/2; DET1,

\section{REFERENCES}

Ahloowalia, B. S., Maluszynski, M., and Nichterlein, K. (2004). Global impact of mutation-derived varieties. Euphytica 135, 187-204. doi: 10.1023/B:EUPH.0000014914.85465.4f

Ahmad, M., Jarillo, J. A., Klimczak, L. J., Landry, L. G., Peng, T., Last, R. L., et al. (1997). An enzyme similar to animal type II photolyases mediates photoreactivation in Arabidopsis. Plant Cell 9, 199-207. doi: 10.1105/tpc.9.2.199

Aklilu, B. B., Sonderquist, R. S., and Culligan, K. M. (2014). Genetic analysis of the replication protein a large subunit family in Arabidopsis reveals unique and overlapping roles in DNA repair, meiosis and DNA replication. Nucleic Acids Res. 42, 3104-3118. doi: 10.1093/nar/gkt1292

Akutsu, N., Iijima, K., Hinata, T., and Tauchi, H. (2007). Characterization of the plant homolog of Nijmegen breakage syndrome 1: involvement in DNA
De-etiolated1; DNA-PKcs kinase, DNA-Dependent Protein Kinase catalytic subunit; DOT1L, DOT1-like histone H3K79 methyltransferase; E2Fe/DEL1, atypical E2F transcription factor DP-E2F-like1; ELL, Eleven-nineteen lysine-rich leukemia (Elongation factor RNA polymerase II); ERCC1, Excision Repair Cross-Complementation Group 1; EXO1, Exonuclease1; FACT, Facilitates chromatin transcription; FAD2, Fatty acid desaturation 2; FANCM, Fanconi anemia complementation group M; FEN1, Flap structure-specific endonuclease 1; FPG, Formamidopyrimidine-DNA glycosylase; GTF2H2, General transcription factor $\mathrm{IIH}$, polypeptide 2; $\mathrm{H}$, Histone; $\mathrm{H} 2 \mathrm{AX}$, Variant histone $\mathrm{H} 2 \mathrm{~A} ; \gamma \mathrm{H} 2 \mathrm{AX}$, gamma-H2AX (phosphorylated H2AX); HAT p300, Histone acetyltransferase p300; HIRA, Histone Cell Cycle Regulator; HMGN1, High Mobility Group Nucleosome Binding Domain 1; HR23B, UV excision repair protein RAD23 homolog B; HY5, Elongated hypocotyl5; HYH, HY5-homolog; KU70, X-ray cross complementing 6; KU80, $\mathrm{X}$-ray cross complementing 5; LIG1, Ligase 1; LIGIV, Ligase 4; MRE11, Meiotic Recombination 11; MUS81, MMS and UVsensitive protein 81 (Crossover junction endonuclease); MutS/L, Mutator S/L; MLH, MutL homolog; MSH, MutS homolog; NBS1, Nijmegen breakage syndrome1; OGG1, Oxoguanine glycosylase; p53, Tumor protein 53; PARP, Poly (ADP-ribose) Polymerase; PCNA, Proliferating cell nuclear antigen; PHR1, CPD photolyase gene; PMS2, Postmeiotic Segregation Increased 2 (DNA Mismatch Repair Protein); POL $\beta$, DNA polymerase beta; Polymerase $\delta$, DNA polymerase delta; POL $\lambda$, DNA polymerase lambda; RAD, Radiation sensitive; RecA, Recombination A; RECQ, ATP-dependent DNA helicase RecQ; RECQ4A, ATPdependent DNA helicase Q-like 4A; RPII, RNA polymerase II; RPA, Replication protein A; RFC, Replication factor C; ROS1, Repressor of silencing1; SOG1, Suppressor of gamma response 1; SWI2/SNF2, SWItch/Sucrose Non-Fermentable; TFB1A, General transcription and DNA repair factor IIH B subunit 1-1; TFB5, General transcription factor IIH, polypeptide 5; TFIIH, Transcription factor II Human; TFIIS, Transcript elongation factor IIS; TTDA, Trichothiodystrophy group A; UVH6, Ultraviolet hypersensitive 6; UVR3, 6-4 photolyase gene; UVR8, UV resistance locus8; XRCC, X-ray repair cross complementing; XAB2, XPA binding protein 2; XLF, XRCC4like factor; XPA-G, Xeroderma pigmentosum complementation group A-G; ZDP, Zinc finger DNA 3'-phosphoesterase.

repair and recombination. Biochem. Biophys. Res. Commun. 353, 394-398. doi: 10.1016/j.bbrc.2006.12.030

Al Khateeb, W., and Schroeder, D. (2009). Overexpression of Arabidopsis damaged DNA binding protein 1A (DDB1A) enhances UV tolerance. Plant Mol. Biol. 70, 371-383. doi: 10.1007/s11103-009-9479-9

Ali, R. B., Teo, A. K. C., Oh, H.-K., Chuang, L. S. H., Ayi, T.-C., and Li, B. F. L. (1998). Implication of localization of human DNA repair enzyme O 6-Methylguanine-DNA methyltransferase at active transcription sites in transcription-repair coupling of the mutagenic O 6-Methylguanine lesion. Mol. Cell. Biol. 18, 1660-1669.

Alpen, E. L. (1998). “Chapter 6 - radiation chemistry," in Radiation Biophysics, 2nd Edn., ed. E. L. Alpen (San Diego: Academic Press), 104-131.

Amiard, S., Charbonnel, C., Allain, E., Depeiges, A., White, C. I., and Gallego, M. E. (2010). Distinct roles of the ATR kinase and the Mre11-Rad50-Nbs1 
complex in the maintenance of chromosomal stability in Arabidopsis. Plant Cell 22, 3020-3033. doi: 10.1105/tpc.110.078527

Amiard, S., Depeiges, A., Allain, E., White, C. I., and Gallego, M. E. (2011). Arabidopsis ATM and ATR Kinases prevent propagation of genome damage caused by telomere dysfunction. Plant Cell 23, 4254-4265. doi: 10.1105/tpc.111.092387

Atwood, S. E., O’Rourke, J. A., Peiffer, G. A., Yin, T., Majumder, M., Zhang, C., et al. (2014). Replication protein A subunit 3 and the iron efficiency response in soybean. Plant Cell Environ. 7, 213-234. doi: 10.1111/pce.12147

Azari, R., Reuveni, M., Evenor, D., Nahon, S., Shlomo, H., Chen, L., et al. (2010). Overexpression of UV-DAMAGED DNA BINDING PROTEIN 1 links plant development and phytonutrient accumulation in high pigment-1 tomato. J. Exp. Bot. 61, 3627-3637. doi: 10.1093/jxb/erq176

Balestrazzi, A., Confalonieri, M., Macovei, A., Donà, M., and Carbonera, D. (2011). Genotoxic stress and DNA repair in plants: emerging functions and tools for improving crop productivity. Plant Cell Rep. 30, 287-295. doi: 10.1007/s00299010-0975-9

Baranczewski, P., Nehls, P., Rieger, R., Pich, U., Rajewsky, M. F., and Schubert, I. (1997a). Formation and repair of O6-methylguanine in recombination hot spots of plant chromosomes. Environ. Mol. Mutagen. 29, 394-399.

Baranczewski, P., Nehls, P., Rieger, R., Rajewsky, M. F., and Schubert, I. (1997b). Removal of O6-methylguanine from plant DNA in vivo is accelerated under conditions of clastogenic adaptation. Environ. Mol. Mutagen. 29, 400-405.

Batschauer, A. (1993). A plant gene for photolyase: an enzyme catalyzing the repair of UV-light-induced DNA damage. Plant J. 4, 705-709. doi: 10.1046/j.1365313X.1993.04040705.x

Bessho, T. (2003). Induction of DNA replication-mediated double strand breaks by psoralen DNA interstrand cross-links. J. Biol. Chem. 278, 5250-5254. doi: 10.1074/jbc.M212323200

Biedermann, S., and Hellmann, H. (2010). The DDB1a interacting proteins ATCSA-1 and DDB2 are critical factors for UV-B tolerance and genomic integrity in Arabidopsis thaliana. Plant J. 62, 404-415. doi: 10.1111/j.1365313X.2010.04157.x

Bleuyard, J.-Y., Gallego, M. E., Savigny, F., and White, C. I. (2005). Differing requirements for the Arabidopsis Rad51 paralogs in meiosis and DNA repair. Plant J. 41, 533-545. doi: 10.1111/j.1365-313X.2004.02318.x

Bleuyard, J.-Y., Gallego, M. E., and White, C. I. (2006). Recent advances in understanding of the DNA double-strand break repair machinery of plants. DNA Repair 5, 1-12. doi: 10.1016/j.dnarep.2005.08.017

Boboila, C., Alt, F. W., and Schwer, B. (2012). "Chapter one - classical and alternative end-joining pathways for repair of lymphocyte-specific and general DNA double-strand breaks," in Advances in Immunology, ed. W. A. Frederick (New York, NY: Academic Press), 1-49.

Boesch, P., Ibrahim, N., Paulus, F., Cosset, A., Tarasenko, V., and Dietrich, A. (2009). Plant mitochondria possess a short-patch base excision DNA repair pathway. Nucleic Acids Res. 37, 5690-5700. doi: 10.1093/nar/gkp606

Boltz, K. A., Jasti, M., Townley, J. M., and Shippen, D. E. (2014). Analysis of poly(ADP-Ribose) polymerases in Arabidopsis telomere biology. PLoS ONE 9:e88872. doi: 10.1371/journal.pone.0088872

Bonner, W. M. (2003). Low-dose radiation: thresholds, bystander effects, and adaptive responses. Proc. Natl. Acad. Sci. U.S.A. 100, 4973-4975. doi: 10.1073/pnas.1031538100

Bowen, N., Smith, C. E., Srivatsan, A., Willcox, S., Griffith, J. D., and Kolodner, R. D. (2013). Reconstitution of long and short patch mismatch repair reactions using Saccharomyces cerevisiae proteins. Proc. Natl. Acad. Sci. U.S.A. 110, 18472-18477. doi: 10.1073/pnas.1318971110

Boyko, A., Filkowski, J., Hudson, D., and Kovalchuk, I. (2006). Homologous recombination in plants is organ specific. Mutat. Res. 595, 145-155. doi: 10.1016/j.mrfmmm.2005.11.009

Boyko, A., Filkowski, J., and Kovalchuk, I. (2005). Homologous recombination in plants is temperature and day-length dependent. Mutat. Res. 572, 73-83. doi: 10.1016/j.mrfmmm.2004.12.011

Boyko, A., and Kovalchuk, I. (2011). Genetic and epigenetic effects of plantpathogen interactions: an evolutionary perspective. Mol. Plant 4, 1014-1023. doi: $10.1093 / \mathrm{mp} / \mathrm{ssr} 022$

Bray, C. M., and West, C. E. (2005). DNA repair mechanisms in plants: crucial sensors and effectors for the maintenance of genome integrity. New Phytol. 168, 511-528. doi: 10.1111/j.1469-8137.2005.01548.x
Brettel, K., and Byrdin, M. (2010). Reaction mechanisms of DNA photolyase. Curr. Opin. Struct. Biol. 20, 693-701. doi: 10.1016/j.sbi.2010.07.003

Britt, A. B. (1995). Repair of DNA damage induced by ultraviolet radiation. Plant Physiol. 108, 891-896. doi: 10.1104/pp.108.3.891

Britt, A. B. (1996). DNA DAMAGE AND REPAIR IN PLANTS. Annu. Rev. Plant Physiol. Plant Mol. Biol. 47, 75-100. doi: 10.1146/annurev.arplant.47.1.75

Britt, A. B. (1999). Molecular genetics of DNA repair in higher plants. Trends Plant Sci. 4, 20-25. doi: 10.1016/S1360-1385(98)01355-7

Britt, A. B. (2002). Repair of damaged bases. Arabidopsis Book 1:e0005. doi: $10.1199 /$ tab.0005

Britt, A. B. (2004). Repair of DNA damage induced by solar UV. Photosynth. Res. 81, 105-112. doi: 10.1023/B:PRES.0000035035.12340.58

Britt, A. B., Chen, J. J., Wykoff, D., and Mitchell, D. (1993). A UV-sensitive mutant of Arabidopsis defective in the repair of pyrimidine-pyrimidinone(6-4) dimers. Science 261, 1571-1574. doi: 10.1126/science.8372351

Britt, A. B., and Fiscus, E. L. (2003). Growth responses of Arabidopsis DNA repair mutants to solar irradiation. Physiol. Plant. 118, 183-192. doi: 10.1034/j.13993054.2003.00062.x

Brown, B. A., and Jenkins, G. I. (2008). UV-B signaling pathways with different fluence-rate response profiles are distinguished in mature Arabidopsis leaf tissue by requirement for UVR8. HY5, and HYH. Plant Physiol. 146, 576-588. doi: 10.1104/pp.107.108456

Bryant, P. E. (1990). "Restriction endonuclease- and radiation-induced DNA double-strand breaks and chromosomal aberrations: similarities and differences," in Chromosomal Aberrations, eds G. Obe and A. T. Natarajan (Berlin: Springer), 61-69.

Bundock, P., and Hooykaas, P. (2002). Severe developmental defects, hypersensitivity to DNA-damaging agents, and lengthened telomeres in Arabidopsis MRE11 mutants. Plant Cell 14, 2451-2462.

Burns, J. A., Dreij, K., Cartularo, L., and Scicchitano, D. A. (2010). O6Methylguanine induces altered proteins at the level of transcription in human cells. Nucleic Acids Res. 38, 8178-8187. doi: 10.1093/nar/ gkq706

Campi, M., D'Andrea, L., Emiliani, J., and Casati, P. (2012). Participation of chromatin-remodeling proteins in the repair of ultraviolet-B-damaged DNA. Plant Physiol. 158, 981-995. doi: 10.1104/pp.111.191452

Cannan, W. J., Tsang, B. P., Wallace, S. S., and Pederson, D. S. (2014). Nucleosomes suppress the formation of double-strand dna breaks during attempted base excision repair of clustered oxidative damages. J. Biol. Chem. 289, 1988-1993. doi: 10.1074/jbc.M114.571588

Cannon, G., Hedrick, L., and Heinhorst, S. (1995). Repair mechanisms of UVinduced DNA damage in soybean chloroplasts. Plant Mol. Biol. 29, 1267-1277. doi: 10.1007/BF00020467

Casati, P., Campi, M., Chu, F., Suzuki, N., Maltby, D., Guan, S., et al. (2008). Histone acetylation and chromatin remodeling are required for UV-Bdependent transcriptional activation of regulated genes in maize. Plant Cell 20, 827-842. doi: 10.1105/tpc.107.056457

Castells, E., Molinier, J., Drevensek, S., Genschik, P., Barneche, F., and Bowler, C. (2010). det1-1-induced UV-C hyposensitivity through UVR3 and PHR1 photolyase gene over-expression. Plant J. 63, 392-404. doi: 10.1111/j.1365313X.2010.04249.X

Chang, W., Wang, Y., Liu, P., Tsai, Y., Kong, L., Lin, C., et al. (2008). Regulation of Ku gene promoters in Arabidopsis by hormones and stress. Funct. Plant Biol. 35, 265-280. doi: 10.1016/j.plantsci.2013.08.008

Chao, Q., Sullivan, C. D., Getz, J. M., Gleason, K. B., Sass, P. M., Nicolaides, N. C., et al. (2005). Rapid generation of plant traits via regulation of DNA mismatch repair. Plant Biotechnol. J. 3, 399-407. doi: 10.1111/j.1467-7652.2005.00133.x

Charbonnel, C., Allain, E., Gallego, M. E., and White, C. I. (2011). Kinetic analysis of DNA double-strand break repair pathways in Arabidopsis. DNA Repair 10, 611-619. doi: 10.1016/j.dnarep.2011.04.002

Charbonnel, C., Gallego, M. E., and White, C. I. (2010). Xrccl-dependent and Kudependent DNA double-strand break repair kinetics in Arabidopsis plants. Plant J. 64, 280-290. doi: 10.1111/j.1365-313X.2010.04331.x

Chen, J. J., Jiang, C. Z., and Britt, A. B. (1996). Little or no repair of cyclobutyl pyrimidine dimers is observed in the organellar genomes of the young Arabidopsis seedling. Plant Physiol. 111, 19-25.

Chen, J., and Stubbe, J. (2005). Bleomycins: towards better therapeutics. Nat. Rev. Cancer 5, 102-112. doi: 10.1038/nrc1547 
Chen, J. J., Mitchell, D. L., and Britt, A. B. (1994). A light-dependent pathway for the elimination of UV-induced pyrimidine (6-4) pyrimidinone photoproducts in Arabidopsis. Plant Cell 6, 1311-1317. doi: 10.1105/tpc.6.9.1311

Christian, M., Cermak, T., Doyle, E. L., Schmidt, C., Zhang, F., Hummel, A., et al. (2010). Targeting DNA double-strand breaks with TAL effector nucleases. Genetics 186, 757-761. doi: 10.1534/genetics.110.120717

Cooke, M. S., Evans, M. D., Dizdaroglu, M., and Lunec, J. (2003). Oxidative DNA damage: mechanisms, mutation, and disease. FASEB J. 17, 1195-1214. doi: 10.1096/fj.02-0752rev

Córdoba-Cañero, D., Morales-Ruiz, T., Roldán-Arjona, T., and Ariza, R. R. (2009). Single-nucleotide and long-patch base excision repair of DNA damage in plants. Plant J. 60, 716-728. doi: 10.1111/j.1365-313X.2009.03994.x

Córdoba-Cañero, D., Roldán-Arjona, T., and Ariza, R. R. (2011). Arabidopsis ARP endonuclease functions in a branched base excision DNA repair pathway completed by LIG1. Plant J. 68, 693-702. doi: 10.1111/j.1365313X.2011.04720.x

Córdoba-Cañero, D., Roldán-Arjona, T., and Ariza, R. R. (2014). Arabidopsis ZDP DNA 3'-phosphatase and ARP endonuclease function in 8-oxoG repair initiated by FPG and OGG1 DNA glycosylases. Plant J. 79, 824-834. doi: $10.1111 /$ tpj. 12588

Costa, R. M. A., Lima, W. C., Vogel, C. I. G., Berra, C. M., Luche, D. D., Medina-Silva, R., et al. (2001). DNA repair-related genes in sugarcane expressed sequence tags (ESTs). Genet. Mol. Biol. 24, 131-140. doi: 10.1590/S141547572001000100018

Culligan, K. M., and Hays, J. B. (2000). Arabidopsis MutS Homologs-AtMSH2, AtMSH3, AtMSH6, and a Novel AtMSH7-Form Three Distinct Protein Heterodimers with Different Specificities for Mismatched DNA. Plant Cell 12, 991-1002.

Culligan, K. M., Meyer-Gauen, G., Lyons-Weiler, J., and Hays, J. B. (2000). Evolutionary origin, diversification and specialization of eukaryotic MutS homolog mismatch repair proteins. Nucleic Acids Res. 28, 463-471. doi: 10.1093/nar/28.2.463

Culligan, K. M., Robertson, C. E., Foreman, J., Doerner, P., and Britt, A. B. (2006). ATR and ATM play both distinct and additive roles in response to ionizing radiation. Plant J. 48, 947-961. doi: 10.1111/j.1365-313X.2006.02931.x

Culligan, K., Tissier, A., and Britt, A. (2004). ATR regulates a G2-phase cellcycle checkpoint in Arabidopsis thaliana. Plant Cell 16, 1091-1104. doi: $10.1105 /$ tpc.018903

Curtis, M. J., and Hays, J. B. (2011). Cooperative responses of DNA-damageactivated protein kinases ATR and ATM and DNA translesion polymerases to replication-blocking DNA damage in a stem-cell niche. DNA Repair. 10, 1272-1281. doi: 10.1016/j.dnarep.2011.10.001

Dany, A.-L., Douki, T., Triantaphylides, C., and Cadet, J. (2001). Repair of the main UV-induced thymine dimeric lesions within Arabidopsis thaliana DNA: evidence for the major involvement of photoreactivation pathways. J. Photochem. Photobiol. B Biol. 65, 127-135. doi: 10.1016/S10111344(01)00254-8

Daoudal-Cotterell, S., Gallego, M. E., and White, C. I. (2002). The plant Rad50-Mre11 protein complex. FEBS Lett. 516, 164-166. doi: 10.1016/S00145793(02)02536-X

de Lange, O., Binder, A., and Lahaye, T. (2014). From dead leaf, to new life: TAL effectors as tools for synthetic biology. Plant J. 78, 753-771. doi: $10.1111 /$ tpj. 12431

De Silva, I. U., McHugh, P. J., Clingen, P. H., and Hartley, J. A. (2000). Defining the roles of nucleotide excision repair and recombination in the repair of dna interstrand cross-links in mammalian cells. Mol. Cell. Biol. 20, 7980-7990. doi: 10.1128/MCB.20.21.7980-7990.2000

Dion, É, Li, L., Jean, M., and Belzile, F. (2007). An Arabidopsis MLH1 mutant exhibits reproductive defects and reveals a dual role for this gene in mitotic recombination. Plant J. 51, 431-440. doi: 10.1111/j.1365-313X.2007.0 3145.x

Doutriaux, M. P., Couteau, F., Bergounioux, C., and White, C. (1998). Isolation and characterisation of the RAD51 and DMC1 homologs from Arabidopsis thaliana. Mol. Gen. Genet. 257, 283-291. doi: 10.1007/s004380050649

Draper, C. K., and Hays, J. B. (2000). Replication of chloroplast, mitochondrial and nuclear DNA during growth of unirradiated and UVB-irradiated Arabidopsis leaves. Plant J. 23, 255-265. doi: 10.1046/j.1365-313x.2000.00776.x
Dubest, S., Gallego, M. E., and White, C. I. (2002). Role of the AtRadlp endonuclease in homologous recombination in plants. EMBO Rep. 3, 10491054. doi: 10.1093/embo-reports/kvf211

Dubest, S., Gallego, M. E., and White, C. I. (2004). Roles of the AtErccl protein in recombination. Plant J. 39, 334-342. doi: 10.1111/j.1365-313X.2004.02136.x

Durbeej, B., and Eriksson, L. A. (2003). On the formation of cyclobutane pyrimidine dimers in UV-irradiated DNA: why are thymines more reactive? Photochem. Photobiol. 78, 159-167. doi: 10.1562/0031-8655(2003)0780159OTFOCP2.0.CO2

Edlinger, B., and Schlögelhofer, P. (2011). Have a break: determinants of meiotic DNA double strand break (DSB) formation and processing in plants. J. Exp. Bot. 62, 1545-1563. doi: 10.1093/jxb/erq421

Escargueil, A. E., Soares, D. G., Salvador, M., Larsen, A. K., and Henriques, J. A. P. (2008). What histone code for DNA repair? Mutat. Res. 658, 259-270. doi: 10.1016/j.mrrev.2008.01.004

Eschbach, V., and Kobbe, D. (2014). Different replication protein a complexes of Arabidopsis thaliana have different DNA-binding properties as a function of heterotrimer composition. Plant Cell Physiol. 55, 1460-1472. doi: 10.1093/pcp/pcu076

Fattah, F., Lee, E. H., Weisensel, N., Wang, Y., Lichter, N., and Hendrickson, E. A. (2010). Ku regulates the non-homologous end joining pathway choice of DNA double-strand break repair in human somatic cells. PLoS Genet. 6:e1000855. doi: 10.1371/journal.pgen.1000855

Feng, Z., Zhang, B., Ding, W., Liu, X., Yang, D.-L., Wei, P., et al. (2013). Efficient genome editing in plants using a CRISPR/Cas system. Cell Res. 23, 1229-1232. doi: $10.1038 / \mathrm{cr} .2013 .114$

Feuerhahn, S., and Egly, J.-M. (2008). Tools to study DNA repair: what's in the box? Trends Genet. 24, 467-474. doi: 10.1016/j.tig.2008.07.003

Fidantsef, A. L., and Britt, A. B. (2012). Preferential repair of the transcribed DNA strand in plants. Front. Plant Sci. 2:105. doi: 10.3389/fpls.2011.00105

Fina, J. P., and Casati, P. (2015). HAG3, a histone acetyltransferase, affects UV-B responses by negatively regulating the expression of DNA repair enzymes and sunscreen content in Arabidopsis thaliana. Plant Cell Physiol. 56, 1388-1400. doi: $10.1093 / \mathrm{pcp} / \mathrm{pcv} 054$

Forster, B. P., and Shu, Q. Y. (2012). Plant Mutation Breeding and Biotechnology. Wallingford: CAB International.

Fousteri, M., Vermeulen, W., van Zeeland, A. A., and Mullenders, L. H. F. (2006). Cockayne syndrome A and B proteins differentially regulate recruitment of chromatin remodeling and repair factors to stalled RNA polymerase II in vivo. Mol. Cell 23, 471-482. doi: 10.1016/j.molcel.2006.06.029

Friesner, J. D., Liu, B., Culligan, K., and Britt, A. B. (2005). Ionizing radiationdependent $\gamma$-H2AX focus formation requires ataxia telangiectasia mutated and ataxia telangiectasia mutated and Rad3-related. Mol. Biol. Cell 16, 2566-2576. doi: 10.1091/mbc.E04-10-0890

Fuss, J. O., and Tainer, J. A. (2011). XPB and XPD helicases in TFIIH orchestrate DNA duplex opening and damage verification to coordinate repair with transcription and cell cycle via CAK kinase. DNA Repair. 10, 697-713. doi: 10.1016/j.dnarep.2011.04.028

Gallego, M. E., Jalut, N., and White, C. I. (2003). Telomerase dependence of telomere lengthening in ku80 mutant Arabidopsis. Plant Cell 15, 782-789. doi: $10.1105 /$ tpc.008623

Gallego, M. E., Jeanneau, M., Granier, F., Bouchez, D., Bechtold, N., and White, I. (2001). Disruption of the Arabidopsis RAD50 gene leads to plant sterility and MMS sensitivity. Plant J. 25, 31-41. doi: 10.1111/j.1365-313X.2001.00928.x

Gallego, M. E., and White, C. I. (2001). RAD50 function is essential for telomere maintenance in Arabidopsis. Proc. Natl. Acad. Sci. U.S.A. 98, 1711-1716. doi: 10.1073/pnas.98.4.1711

Galles, C., and Spampinato, C. (2013). Yeast mutator phenotype enforced by Arabidopsis PMS1 expression. Mol. Biol. Rep. 40, 2107-2114. doi: 10.1007/s11033-012-2269-5

Ganpudi, A. L., and Schroeder, D. F. (2013). Genetic interactions of Arabidopsis thaliana damaged DNA binding protein 1B (DDB1B) with DDB1A. DET1, and COP1. G3 (Bthesda) 3, 493-503. doi: 10.1534/g3.112.005249

Gao, M., Wei, W., Li, M. M., Wu, Y. S., Ba, Z., Jin, K. X., et al. (2014). Ago2 facilitates Rad51 recruitment and DNA double-strand break repair by homologous recombination. Cell Res. 24, 532-541. doi: 10.1038/cr. 2014.36 
Garcia, V., Bruchet, H., Camescasse, D., Granier, F., Bouchez, D., and Tissier, A. (2003). AtATM is essential for meiosis and the somatic response to DNA damage in plants. Plant Cell 15, 119-132. doi: 10.1105/tpc.006577

Garcia, V., Salanoubat, M., Choisne, N., and Tissier, A. (2000). An ATM homologue from Arabidopsis thaliana: complete genomic organisation and expression analysis. Nucleic Acids Res. 28, 1692-1699. doi: 10.1093/nar/28.8.1692

Georgieva, M., and Stoilov, L. (2008). Assessment of DNA strand breaks induced by bleomycin in barley by the comet assay. Environ. Mol. Mutagen. 49, 381-387. doi: $10.1002 / \mathrm{em} .20396$

Gisler, B., Salomon, S., and Puchta, H. (2002). The role of double-strand breakinduced allelic homologous recombination in somatic plant cells. Plant J. 32, 277-284. doi: 10.1046/j.1365-313X.2002.01421.x

Goff, S. A., Ricke, D., Lan, T.-H., Presting, G., Wang, R., Dunn, M., et al. (2002). A draft sequence of the rice genome (Oryza sativa L. ssp. japonica). Science 296, 92-100. doi: 10.1126/science.1068275

Golubov, A., Yao, Y., Maheshwari, P., Bilichak, A., Boyko, A., Belzile, F., et al. (2010). Microsatellite instability in Arabidopsis increases with plant development. Plant Physiol. 154, 1415-1427. doi: 10.1104/pp.110.162933

Gómez, R., and Spampinato, C. P. (2013). Mismatch recognition function of Arabidopsis thaliana Muts $\gamma$. DNA Repair 12, 257-264. doi: 10.1016/j.dnarep.2013.01.002

Gorbunova, V., and Levy, A. A. (1999). How plants make ends meet: DNA double-strand break repair. Trends Plant Sci. 4, 263-269. doi: 10.1016/S13601385(99)01430-2

Grice, M. D., Osmond, M. J., Stewart, M., Vonarx, E. J., and Kunz, B. A. (2007). "Roles of plant transcription factor IIH subunit homologs in nucleotide excision repair and transcription," in New Research on DNA Repair, ed. B. R. Landseer (New York, NY: Nova Science Publishers Inc.), 251-272.

Gruszka, D., Marzec, M., and Szarejko, I. (2012). The barley EST DNA replication and repair database (bEST-DRRD) as a tool for the identification of the genes involved in DNA replication and repair. BMC Plant Biol. 12:88. doi: 10.1186/1471-2229-12-88

Gu, J., Wang, Q., Cui, M., Han, B., Guo, H., Zhao, L., et al. (2014). Cloning and characterization of Ku70 and Ku80 homologues involved in DNA repair process in wheat (Triticum aestivum L.). Plant Genet. Resour. 12, S99-S103. doi: $10.1017 /$ S1479262114000367

Hada, M., Hino, K., Buchholz, G., Goss, J., Wellmann, E., and Shin, M. (2000). Assay of DNA photolyase activity in spinach leaves in relation to cell compartmentation-evidence for lack of DNA photolyase in chloroplasts. Biosci. Biotechnol. Biochem. 64, 1288-1291. doi: 10.1271/bbb. 64.1288

Hamada, K., Inoue, M., Tanaka, A., and Watanabe, H. (1999). Potato virus Y-resistant mutation induced by the combination treatment of ion beam exposure and anther culture in Nicotiana tabacum L. Plant Biotechnol. 16, 285-289. doi: 10.5511/plantbiotechnology.16.285

Hanawalt, P. C. (2002). Subpathways of nucleotide excision repair and their regulation. Oncogene 21, 8949-8956. doi: 10.1038/sj.onc.1206096

Hartung, F., Plchová, H., and Puchta, H. (2000). Molecular characterisation of RecQ homologues in Arabidopsis thaliana. Nucleic Acids Res. 28, 4275-4282. doi: 10.1093/nar/28.21.4275

Hartung, F., and Puchta, H. (1999). Isolation of the complete cDNA of the Mre11 homologue of Arabidopsis (Accession No. AJ243822) indicates conservation of DNA recombination mechanisms between plants and other eucaryotes. (PGR99-132). Plant Physiol. 121:312.

Haun, W., Coffman, A., Clasen, B. M., Demorest, Z. L., Lowy, A., Ray, E., et al. (2014). Improved soybean oil quality by targeted mutagenesis of the fatty acid desaturase 2 gene family. Plant Biotechnol. J. 12, 934-940. doi: 10.1111/pbi.12201

Hays, J. B. (2002). Arabidopsis thaliana, a versatile model system for study of eukaryotic genome-maintenance functions. DNA Repair. 1, 579-600. doi: 10.1016/S1568-7864(02)00093-9

Hidema, J., Kumagai, T., and Sutherland, B. M. (2000). UV radiation-sensitive norin 1 rice contains defective cyclobutane pyrimidine dimer photolyase. Plant Cell 12, 1569-1578. doi: 10.1105/tpc.12.9.1569

Hidema, J., Kumagai, T., Sutherland, J. C., and Sutherland, B. M. (1997). Ultraviolet B-sensitive rice cultivar deficient in cyclobutyl pyrimidine dimer repair. Plant Physiol. 113, 39-44.
Hidema, J., Teranishi, M., Iwamatsu, Y., Hirouchi, T., Ueda, T., Sato, T., et al. (2005). Spontaneously occurring mutations in the cyclobutane pyrimidine dimer photolyase gene cause different sensitivities to ultraviolet-B in rice. Plant J. 43, 57-67. doi: 10.1111/j.1365-313X.2005.02428.x

Hirouchi, T., Nakajima, S., Najrana, T., Tanaka, M., Matsunaga, T., Hidema, J., et al. (2003). A gene for a class II DNA photolyase from Oryza sativa: cloning of the cDNA by dilution-amplification. Mol. Genet. Genomics 269, 508-516. doi: 10.1007/s00438-003-0856-9

Hitomi, K., Arvai, A. S., Yamamoto, J., Hitomi, C., Teranishi, M., Hirouchi, T., et al. (2012). Eukaryotic class II cyclobutane pyrimidine dimer photolyase structure reveals basis for improved ultraviolet tolerance in plants. J. Biol. Chem. 287, 12060-12069. doi: 10.1074/jbc.M111.244020

Hoffman, P. D., Leonard, J. M., Lindberg, G. E., Bollmann, S. R., and Hays, J. B. (2004). Rapid accumulation of mutations during seed-to-seed propagation of mismatch-repair-defective Arabidopsis. Genes Dev. 18, 2676-2685. doi: $10.1101 /$ gad.1217204

Hombauer, H., Srivatsan, A., Putnam, C. D., and Kolodner, R. D. (2011). Mismatch repair, but not heteroduplex rejection, is temporally coupled to DNA replication. Science 334, 1713-1716. doi: 10.1126/science.12 10770

Honda, M., Okuno, Y., Hengel, S. R., Martín-López, J. V., Cook, C. P., Amunugama, R., et al. (2014). Mismatch repair protein hMSH2-hMSH6 recognizes mismatches and forms sliding clamps within a D-loop recombination intermediate. Proc. Natl. Acad. Sci. U.S.A. 111, E316-E325. doi: 10.1073/pnas.1312988111

Ishibashi, T., Kimura, S., and Sakaguchi, K. (2006). A higher plant has three different types of RPA heterotrimeric complex. J. Biochem. (Tokyo) 139, 99-104. doi: 10.1093/jb/mvj014

Ishibashi, T., Kimura, S., Yamamoto, T., Furukawa, T., Takata, K.-I., Uchiyama, Y., et al. (2003). Rice UV-damaged DNA binding protein homologues are most abundant in proliferating tissues. Gene 308, 79-87.

Iwamatsu, Y., Aoki, C., Takahashi, M., Teranishi, M., Ding, Y., Sun, C., et al. (2008). UVB sensitivity and cyclobutane pyrimidine dimer (CPD) photolyase genotypes in cultivated and wild rice species. Photochem. Photobiol. Sci. 7, 311-320. doi: 10.1039/b719034d

Iyama, T., and Wilson, D. M. I. I. I. (2013). DNA repair mechanisms in dividing and non-dividing cells. DNA Repair 12, 620-636. doi: 10.1016/j.dnarep.2013. 04.015

Javaid, S., Manohar, M., Punja, N., Mooney, A., Ottesen, J. J., Poirier, M. G., et al. (2009). Nucleosome remodeling by hMSH2-hMSH6. Mol. Cell. 36, 1086-1094. doi: 10.1016/j.molcel.2009.12.010

Jia, Q., Dulk-Ras, A., Shen, H., Hooykaas, P. J., and de Pater, S. (2013). Poly(ADPribose)polymerases are involved in microhomology mediated back-up nonhomologous end joining in Arabidopsis thaliana. Plant Mol. Biol. 82, 339-351. doi: 10.1007/s11103-013-0065-9

Jiang, C. Z., Yee, J., Mitchell, D. L., and Britt, A. B. (1997a). Photorepair mutants of Arabidopsis. Proc. Natl. Acad. Sci. U.S.A. 94, 7441-7445. doi: 10.1073/pnas.94.14.7441

Jiang, C. Z., Yen, C. N., Cronin, K., Mitchell, D., and Britt, A. B. (1997b). UVand gamma-radiation sensitive mutants of Arabidopsis thaliana. Genetics 147, 1401-1409.

Jiang, W., Zhou, H., Bi, H., Fromm, M., Yang, B., and Weeks, D. P. (2013). Demonstration of CRISPR/Cas9/sgRNA-mediated targeted gene modification in Arabidopsis, tobacco, sorghum and rice. Nucleic Acids Res. 41, e188. doi: $10.1093 /$ nar/gkt780

Jiricny, J. (2013). Postreplicative mismatch repair. Cold Spring Harb. Perspect. Biol. 5:a012633. doi: 10.1101/cshperspect.a012633

Kaiser, G., Kleiner, O., Beisswenger, C., and Batschauer, A. (2009). Increased DNA repair in Arabidopsis plants overexpressing CPD photolyase. Planta 230, 505-515. doi: 10.1007/s00425-009-0962-y

Kamileri, I., Karakasilioti, I., and Garinis, G. A. (2012). Nucleotide excision repair: new tricks with old bricks. Trends Genet. 28, 566-573. doi: 10.1016/j.tig.2012.06.004

Keeney, S. (2001). Mechanism and control of meiotic recombination initiation. Curr. Top. Dev. Biol. 52, 1-53. doi: 10.1016/s0070-2153(01)52008-6

Kharkwal, M. C. and Shu, Q. Y. (2009). "The role of induced mutations in world food security. In: induced Plant Mutations in the Genomic Era," in Proceedings 
of an International Joint FAO/IAEA Symposium, Vienna: International Atomic Energy Agency, 33-38.

Kim, K., Yun, M., Shin, J., Kang, Y., Kim, M., and Lee, S.-H. (2015). Underlying genetic variation in the response of cultivated and wild soybean to enhanced ultraviolet-B radiation. Euphytica 202, 207-217.

Kimura, S., Tahira, Y., Ishibashi, T., Mori, Y., Mori, T., Hashimoto, J., et al. (2004). DNA repair in higher plants; photoreactivation is the major DNA repair pathway in non-proliferating cells while excision repair (nucleotide excision repair and base excision repair) is active in proliferating cells. Nucleic Acids Res. 32, 2760-2767. doi: 10.1093/nar/gkh591

Kirik, A., Salomon, S., and Puchta, H. (2000). Species-specific double-strand break repair and genome evolution in plants. EMBO J. 19, 5562-5566. doi: 10.1093/emboj/19.20.5562

Kozak, J., West, C. E., White, C., da Costa-Nunes, J. A., and Angelis, K. J. (2009). Rapid repair of DNA double strand breaks in Arabidopsis thaliana is dependent on proteins involved in chromosome structure maintenance. DNA Repair 8, 413-419. doi: 10.1016/j.dnarep.2008.11.012

Kunz, B. A., Dando, P. K., Grice, D. M., Mohr, P. G., Schenk, P. M., and Cahill, D. M. (2008). UV-Induced DNA damage promotes resistance to the biotrophic pathogen hyaloperonospora parasitica in Arabidopsis. Plant Physiol. 148, 1021-1031. doi: 10.1104/pp.108.125435

Kuo, M. T. (1981). Preferential damage of active chromatin by bleomycin. Cancer Res. 41, 2439-2443.

Kwon, Y., and Smerdon, M. J. (2005). DNA repair in a protein-DNA complex: searching for the key to get in. Mutat. Res. 577, 118-130. doi: 10.1016/j.mrfmmm.2005.02.013

Landry, L. G., Stapleton, A. E., Lim, J., Hoffman, P., Hays, J. B., Walbot, V., et al. (1997). An Arabidopsis photolyase mutant is hypersensitive to ultraviolet-B radiation. Proc. Natl. Acad. Sci. U.S.A. 94, 328-332.

Lario, L. D., Botta, P., Casati, P., and Spampinato, C. P. (2015). Role of AtMSH7 in UV-B-induced DNA damage recognition and recombination. J. Exp. Bot. 66, 3019-3026. doi: 10.1093/jxb/eru464

Lario, L. D., Ramirez-Parra, E., Gutierrez, C., Casati, P., and Spampinato, C. P. (2011). Regulation of plant MSH2 and MSH6 genes in the UV-Binduced DNA damage response. J. Exp. Bot. 62, 2925-2937. doi: 10.1093/jxb/ err001

Lario, L. D., Ramirez-Parra, E., Gutierrez, C., Spampinato, C. P., and Casati, P. (2013). ANTI-SILENCING FUNCTION1 proteins are involved in ultraviolet-induced DNA damage repair and are cell cycle regulated by e2f transcription factors in Arabidopsis. Plant Physiol. 162, 1164-1177. doi: 10.1104/pp.112.212837

Lavelle, C., and Foray, N. (2014). Chromatin structure and radiation-induced DNA damage: from structural biology to radiobiology. Int. J. Biochem. Cell Biol. 49, 84-97. doi: 10.1016/j.biocel.2014.01.012

Law, C., and Cheung, P. (2013). "Histone variants and transcription regulation," in Epigenetics: Development and Disease, ed. T. K. Kundu (Amsterdam: Springer), 319-341.

Law, Y. K., Forties, R. A., Liu, X., Poirier, M. G., and Kohler, B. (2013). Sequence-dependent thymine dimer formation and photoreversal rates in double-stranded DNA. Photochem. Photobiol. Sci. 12, 1431-1439. doi: 10.1039/c3pp50078k

Leonard, J. M., Bollmann, S. R., and Hays, J. B. (2003). Reduction of stability of Arabidopsis genomic and transgenic DNA-repeat sequences (Microsatellites) by inactivation of AtMSH2 mismatch-repair function. Plant Physiol. 133, 328-338. doi: 10.1104/pp.103.023952

Li, J.-F., Norville, J. E., Aach, J., McCormack, M., Zhang, D., Bush, J., et al. (2013). Multiplex and homologous recombination-mediated genome editing in Arabidopsis and Nicotiana benthamiana using guide RNA and Cas9. Nat. Biotechnol. 31, 688-691. doi: 10.1038/nbt.2654

Li, L., Jean, M., and Belzile, F. (2006). The impact of sequence divergence and DNA mismatch repair on homeologous recombination in Arabidopsis. Plant J. 45, 908-916. doi: 10.1111/j.1365-313X.2006.02657.x

Li, S., Paulsson, M., and Björn, L. O. (2002). Temperature-dependent formation and photorepair of DNA damage induced by UV-B radiation in suspensioncultured tobacco cells. J. Photochem. Photobiol. B Biol. 66, 67-72. doi: 10.1016/S1011-1344(01)00277-9

Li, W., Chen, C., Markmann-Mulisch, U., Timofejeva, L., Schmelzer, E., Ma, H., et al. (2004). The Arabidopsis AtRAD51 gene is dispensable for vegetative development but required for meiosis. Proc. Natl. Acad. Sci. U.S.A. 101, 1059610601. doi: 10.1073/pnas.0404110101

Liang, L., Flury, S., Kalck, V., Hohn, B., and Molinier, J. (2006). CENTRIN2 Interacts with the Arabidopsis homolog of the human XPC protein (AtRAD4) and contributes to efficient synthesis-dependent repair of bulky DNA lesions. Plant Mol. Biol. 61, 345-356. doi: 10.1007/s11103-006-0016-9

Lieber, M. R. (2010). The mechanism of double-strand DNA break repair by the nonhomologous DNA end-joining pathway. Annu. Rev. Biochem. 79, 181-211. doi: 10.1146/annurev.biochem.052308.093131

Liu, J., Tang, X., Gao, L., Gao, Y., Li, Y., Huang, S., et al. (2012). A role of tomato UV-damaged DNA binding protein 1 (DDB1) in organ size control via an epigenetic manner. PLOS ONE 7:e42621. doi: 10.1371/journal.pone. 0042621

Liu, Z., Hossain, G. S., Islas-Osuna, M. A., Mitchell, D. L., and Mount, D. W. (2000). Repair of UV damage in plants by nucleotide excision repair: Arabidopsis UVH1 DNA repair gene is a homolog of Saccharomyces cerevisiae Rad1. Plant J. 21, 519-528. doi: 10.1046/j.1365-313x.2000.00707.x

Lloyd, A., Milligan, A., Langridge, P., and Able, J. (2007). TaMSH7: a cereal mismatch repair gene that affects fertility in transgenic barley (Hordeum vulgare L.). BMC Plant Biol. 7:67. doi: 10.1186/1471-2229-7-67

Lloyd, A., Plaisier, C. L., Carroll, D., and Drews, G. N. (2005). Targeted mutagenesis using zinc-finger nucleases in Arabidopsis. Proc. Natl. Acad. Sci. U.S.A. 102, 2232-2237. doi: 10.1073/pnas.0409339102

Lloyd, A. H., Wang, D., and Timmis, J. N. (2012). Single molecule PCR reveals similar patterns of non-homologous DSB repair in tobacco and Arabidopsis. PLOS ONE 7:e32255. doi: 10.1371/journal.pone.0032255

Löbrich, M., Shibata, A., Beucher, A., Fisher, A., Ensminger, M., Goodarzi, A. A., et al. (2010). $\gamma \mathrm{H} 2 \mathrm{AX}$ foci analysis for monitoring DNA double-strand break repair: strengths, limitations and optimization. Cell Cycle 9, 662-669. doi: 10.4161/cc.9.4.10764

Lucas-Lledó, J. I., and Lynch, M. (2009). Evolution of mutation rates: phylogenomic analysis of the photolyase/Cryptochrome family. Mol. Biol. Evol. 26, 1143-1153. doi: 10.1093/molbev/msp029

Ly, V., Hatherell, A., Kim, E., Chan, A., Belmonte, M. F., and Schroeder, D. F. (2013). Interactions between Arabidopsis DNA repair genes UVH6. DDB1A, and DDB2 during abiotic stress tolerance and floral development. Plant Sci. 213, 88-97. doi: 10.1016/j.plantsci.2013.09.004

Macovei, A., Balestrazzi, A., Confalonieri, M., Faé, M., and Carbonera, D. (2011). New insights on the barrel medic MtOGG1 and MtFPG functions in relation to oxidative stress response in planta and during seed imbibition. Plant Physiol. Biochem. 49, 1040-1050. doi: 10.1016/j.plaphy.2011.05.007

Mahfouz, M. M., Li, L., Shamimuzzaman, M., Wibowo, A., Fang, X., and Zhu, J.-K. (2011). De novo-engineered transcription activator-like effector (TALE) hybrid nuclease with novel DNA binding specificity creates double-strand breaks. Proc. Natl. Acad. Sci. U.S.A. 108, 2623-2628. doi: 10.1073/pnas.10195 33108

Mandemaker, I. K., Vermeulen, W., and Marteijn, J. A. (2014). Gearing up chromatin. Nucleus 5, 203-210. doi: 10.4161/nucl.29085

Mannuss, A., Dukowic-Schulze, S., Suer, S., Hartung, F., Pacher, M., and Puchta, H. (2010). RAD5A, RECQ4A, and MUS81 have specific functions in homologous recombination and define different pathways of DNA repair in Arabidopsis thaliana. Plant Cell 22, 3318-3330. doi: 10.1105/tpc.110.078568

Mannuss, A., Trapp, O., and Puchta, H. (2012). Gene regulation in response to DNA damage. Biochim. Biophys. Acta 1819, 154-165. doi: 10.1016/j.bbagrm.2011.08.003

Manova, V., Gecheff, K., and Stoilov, L. (2006). Efficient repair of bleomycininduced double-strand breaks in barley ribosomal genes. Mutat. Res. 601, 179-190. doi: 10.1016/j.mrfmmm.2006.07.004

Manova, V., Georgieva, M., Borisov, B., Stoilova, B., Gecheff, K., and Stoilov, L. (2009). "Genomic and gene-specific induction and repair of DNA damage in barley," in Induced Plant Mutations in the Genomics Era, ed. Q. Y. Shu (Rome: Food and Agriculture Organization of the United Nations), 133-136.

Manova, V. I., and Stoilov, L. M. (2003). Induction and recovery of double-strand breaks in barley ribosomal DNA. DNA Repair 2, 983-990. doi: 10.1016/S15687864(03)00095-8

Mao, Y., Zhang, H., Xu, N., Zhang, B., Gou, F., and Zhu, J.-K. (2013). Application of the CRISPR-Cas System for Efficient genome engineering in plants. Mol. Plant 6, 2008-2011. doi: $10.1093 / \mathrm{mp} / \mathrm{sst} 121$ 
Martínez-Macías, M. I., Córdoba-Cañero, D., Ariza, R. R., and Roldán-Arjona, T. (2013). The DNA repair protein XRCC1 functions in the plant DNA demethylation pathway by stimulating cytosine methylation $(5-\mathrm{meC})$ excision, gap tailoring, and DNA ligation. J. Biol. Chem. 288, 5496-5505. doi: 10.1074/jbc.M112.427617

Memisoglu, A., and Samson, L. (2000). Base excision repair in yeast and mammals. Mutat. Res. 451, 39-51. doi: 10.1016/S0027-5107(00)00039-7

Miao, J., Guo, D., Zhang, J., Huang, Q., Qin, G., Zhang, X., et al. (2013). Targeted mutagenesis in rice using CRISPR-Cas system. Cell Res. 23, 1233-1236. doi: $10.1038 / \mathrm{cr} .2013 .123$

Mladenov, E., and Iliakis, G. (2011). Induction and repair of DNA double strand breaks: the increasing spectrum of non-homologous end joining pathways. Mutat. Res. 711, 61-72. doi: 10.1016/j.mrfmmm.2011.02.005

Modrich, P. (2006). Mechanisms in eukaryotic mismatch repair. J. Biol. Chem. 281, 30305-30309. doi: 10.1074/jbc.R600022200

Molinier, J., Lechner, E., Dumbliauskas, E., and Genschik, P. (2008). Regulation and role of Arabidopsis CUL4-DDB1A-DDB2 in maintaining genome integrity upon UV Stress. PLoS Genet. 4:e1000093. doi: 10.1371/journal.pgen.1000093

Molinier, J., Oakeley, E. J., Niederhauser, O., Kovalchuk, I., and Hohn, B. (2005). Dynamic response of plant genome to ultraviolet radiation and other genotoxic stresses. Mutat. Res. 571, 235-247. doi: 10.1016/j.mrfmmm.2004.09.016

Molinier, J., Ramos, C., Fritsch, O., and Hohn, B. (2004). CENTRIN2 modulates homologous recombination and nucleotide excision repair in Arabidopsis. Plant Cell 16, 1633-1643. doi: 10.1105/tpc.021378

Molinier, J., Ries, G., Zipfel, C., and Hohn, B. (2006). Transgeneration memory of stress in plants. Nature 442, 1046-1049. doi: 10.1038/nature05022

Montecucco, A., and Biamonti, G. (2013). Pre-mRNA processing factors meet the DNA damage response. Front. Genet. 4:102. doi: 10.3389/fgene.2013.00102

Moser, J., Kool, H., Giakzidis, I., Caldecott, K., Mullenders, L. H. F., and Fousteri, M. I. (2007). Sealing of chromosomal DNA nicks during nucleotide excision repair requires XRCC1 and DNA ligase III $\alpha$ in a cell-cycle-specific manner. Mol. Cell. 27, 311-323. doi: 10.1016/j.molcel.2007.06.014

Mourgues, S., Gautier, V., Lagarou, A., Bordier, C., Mourcet, A., Slingerland, J., et al. (2013). ELL, a novel TFIIH partner, is involved in transcription restart after DNA repair. Proc. Natl. Acad. Sci. U.S.A. 110, 17927-17932. doi: 10.1073/pnas.1305009110

Mydlikova, Z., Gursky, J., and Pirsel, M. (2010). Transcription factor IIHthe protein complex with multiple functions. Neoplasma 57, 287-290. doi: 10.4149/neo_2010_04_287

Nakagawa, M., Takahashi, S., Tanaka, A., Narumi, I., and Sakamoto, A. N. (2011). Role of AtPol $\zeta$, AtRev1, and AtPoln in UV light-induced mutagenesis in Arabidopsis. Plant Physiol. 155, 414-420. doi: 10.1104/pp.110.166082

Nakajima, S., Sugiyama, M., Iwai, S., Hitomi, K., Otoshi, E., Kim, S.-T., et al. (1998). Cloning and characterization of a gene (UVR3) required for photorepair of 64 photoproducts in Arabidopsis thaliana. Nucleic Acids Res. 26, 638-644. doi: $10.1093 /$ nar/26.2.638

Natarajan, A. T. (2005). Chemical mutagenesis: from plants to human. Curr. Sci. 89:312.

Neal, J. A., and Meek, K. (2011). Choosing the right path: does DNA-PK help make the decision? Mutat. Res. 711, 73-86. doi: 10.1016/j.mrfmmm.2011.02.010

Nekrasov, V., Staskawicz, B., Weigel, D., Jones, J. D. G., and Kamoun, S. (2013). Targeted mutagenesis in the model plant Nicotiana benthamiana using Cas 9 RNA-guided endonuclease. Nat. Biotechnol. 31, 691-693. doi: 10.1038/nbt.2655

Nishizawa-Yokoi, A., Nonaka, S., Saika, H., Kwon, Y.-I., Osakabe, K., and Toki, S. (2012). Suppression of Ku70/80 or Lig4 leads to decreased stable transformation and enhanced homologous recombination in rice. New Phytol. 196, 1048-1059. doi: 10.1111/j.1469-8137.2012.04350.x

Obe, G., Eke, P., and Johannes, C. (1995). Exposure of CHO cells to AluI: comparison of chromosomal aberrations and cell survival. Mutat. Res. 326, 171-174. doi: 10.1016/0027-5107(94)00169-6

Ogi, T., Limsirichaikul, S., Overmeer, R. M., Volker, M., Takenaka, K., Cloney, R., et al. (2010). Three DNA polymerases, recruited by different mechanisms, carry out NER repair synthesis in human cells. Mol. Cell. 37, 714-727. doi: 10.1016/j.molcel.2010.02.009

Oliver, C., Santos, J. L., and Pradillo, M. (2014). On the role of some ARGONAUTE proteins in meiosis and DNA repair in Arabidopsis thaliana. Front. Plant Sci. 5:177. doi: $10.3389 /$ fpls.2014.00177
Orel, N., Kyryk, A., and Puchta, H. (2003). Different pathways of homologous recombination are used for the repair of double-strand breaks within tandemly arranged sequences in the plant genome. Plant J. 35, 604-612. doi: 10.1046/j.1365-313X.2003.01832.x

Osakabe, K., Abe, K., Yamanouchi, H., Takyuu, T., Yoshioka, T., Ito, Y., et al. (2005). Arabidopsis Rad51B is important for double-strand DNA breaks repair in somatic cells. Plant Mol. Biol. 57, 819-833. doi: 10.1007/s11103-005-2187-1

Osakabe, K., Osakabe, Y., and Toki, S. (2010). Site-directed mutagenesis in Arabidopsis using custom-designed zinc finger nucleases. Proc. Natl. Acad. Sci. U.S.A. 107, 12034-12039. doi: 10.1073/pnas.1000234107

Osakabe, K., Yoshioka, T., Ichikawa, H., and Toki, S. (2002). Molecular cloning and characterization of RAD51-like genes from Arabidopsis thaliana. Plant Mol. Biol. 50, 71-81. doi: 10.1023/A:1016047231597

Palomera-Sanchez, Z., and Zurita, M. (2011). Open, repair and close again: chromatin dynamics and the response to UV-induced DNA damage. DNA Repair 10, 119-125. doi: 10.1016/j.dnarep.2010.10.010

Pang, Q., and Hays, J. B. (1991). UV-B-inducible and temperature-sensitive photoreactivation of cyclobutane pyrimidine dimers in Arabidopsis thaliana. Plant Physiol. 95, 536-543. doi: 10.1104/pp.95.2.536

Park, S.-Y., Vaghchhipawala, Z., Vasudevan, B., Lee, L.-Y., Shen, Y., Singer, K., et al. (2015). Agrobacterium T-DNA integration into the plant genome can occur without the activity of key non-homologous end-joining proteins. Plant J. 81, 934-946. doi: 10.1111/tpj.12779

Parry, M. A. J., Madgwick, P. J., Bayon, C., Tearall, K., Hernandez-Lopez, A., Baudo, M., et al. (2009). Mutation discovery for crop improvement. J. Exp. Bot. 60, 2817-2825. doi: 10.1093/jxb/erp189

Pathirana, R. (2011). Plant mutation breeding in agriculture. CAB Rev. 6:32. doi: 10.1079/PAVSNNR20116032

Paull, T. T., Rogakou, E. P., Yamazaki, V., Kirchgessner, C. U., Gellert, M., and Bonner, W. M. (2000). A critical role for histone H2AX in recruitment of repair factors to nuclear foci after DNA damage. Curr. Biol. 10, 886-895. doi: 10.1016/S0960-9822(00)00610-2

Pegg, A. E. (2011). Multifaceted roles of alkyltransferase and related proteins in DNA repair, DNA damage, resistance to chemotherapy, and research tools. Chem. Res. Toxicol. 24, 618-639. doi: 10.1021/tx200031q

Pfeifer, G. P. (1997). Formation and processing of UV photoproducts: effects of DNA sequence and chromatin environment. Photochem. Photobiol. 65, 270-283. doi: 10.1111/j.1751-1097.1997.tb08560.x

Pfeifer, G. P., Drouin, R., Riggs, A. D., and Holmquist, G. P. (1991). In vivo mapping of a DNA adduct at nucleotide resolution: detection of pyrimidine (6-4) pyrimidone photoproducts by ligation-mediated polymerase chain reaction. Proc. Natl. Acad. Sci. U.S.A. 88, 1374-1378. doi: 10.1073/pnas.88. 4.1374

Pokorny, R., Klar, T., Hennecke, U., Carell, T., Batschauer, A., and Essen, L.-O. (2008). Recognition and repair of UV lesions in loop structures of duplex DNA by DASH-type cryptochrome. Proc. Natl. Acad. Sci. U.S.A. 105, 21023-21027. doi: 10.1073/pnas.0805830106

Polyn, S., Willems, A., and De Veylder, L. (2015). Cell cycle entry, maintenance, and exit during plant development. Curr. Opin. Plant Biol. 23, 1-7. doi: 10.1016/j.pbi.2014.09.012

Povirk, L. F., and Finley Austin, M. J. (1991). Genotoxicity of bleomycin. Mutat. Res. 257, 127-143. doi: 10.1016/0165-1110(91)90022-N

Puchta, H. (2005). The repair of double-strand breaks in plants: mechanisms and consequences for genome evolution. J. Exp. Bot. 56, 1-14.

Puchta, H., and Fauser, F. (2014). Synthetic nucleases for genome engineering in plants: prospects for a bright future. Plant J. 78, 727-741. doi: 10.1111/tpj.12338

Puchta, H., and Hohn, B. (1996). From centiMorgans to base pairs: homologous recombination in plants. Trends Plant Sci. 1, 340-348. doi: 10.1016/S13601385(96)82595-0

Puchta, H., and Hohn, B. (2012). In planta somatic homologous recombination assay revisited: a successful and versatile, but delicate tool. Plant Cell 24, 4324-4331. doi: 10.1105/tpc.112.101824

Puchta, H., Swoboda, P., and Hohn, B. (1995). Induction of intrachromosomal homologous recombination in whole plants. Plant J. 7, 203-210. doi: 10.1046/j.1365-313X.1995.7020203.x

Puizina, J., Siroky, J., Mokros, P., Schweizer, D., and Riha, K. (2004). Mre11 Deficiency in Arabidopsis is associated with chromosomal instability in somatic 
cells and spo11-dependent genome fragmentation during meiosis. Plant Cell 16, 1968-1978. doi: 10.1105/tpc.104.022749

Quaite, F. E., Takayanagi, S., Ruffini, J., Sutherland, J. C., and Sutherland, B. M. (1994). DNA damage levels determine cyclobutyl pyrimidine dimer repair mechanisms in alfalfa seedlings. Plant Cell 6, 1635-1641. doi: 10.1105/tpc.6.11.1635

Radziejwoski, A., Vlieghe, K., Lammens, T., Berckmans, B., Maes, S., Jansen, M. A. K., et al. (2011). Atypical E2F activity coordinates PHR1 photolyase gene transcription with endoreduplication onset. $Е M B O ~ J .30,355-363$. doi: 10.1038/emboj.2010.313

Rastogi, R. P., Kumar, A., Tyagi, M. B., and Sinha, R. P. (2010). Molecular mechanisms of ultraviolet radiation-induced DNA damage and repair. J. Nucleic Acids 2010, 592980. doi: 10.4061/2010/592980

Reed, S. H. (2011). Nucleotide excision repair in chromatin: damage removal at the drop of a HAT. DNA Repair 10, 734-742. doi: 10.1016/j.dnarep.2011.04.029

Reyes-Borja, W. O., Sotomayor, I., Garzon, I., Vera, D., Cedeno, M., and Castillo, B. (2007). Alteration of resistance to black sigatoka (Mycosphaerella fijiensis Morelet) in banana by in vitro irradiation using carbon ion-beam. Plant Biotechnol. 24, 349-353. doi: 10.5511/plantbiotechnology.24.349

Ries, G., Buchholz, G., Frohnmeyer, H., and Hohn, B. (2000a). UV-damagemediated induction of homologous recombination in Arabidopsis is dependent on photosynthetically active radiation. Proc. Natl. Acad. Sci. U.S.A. 97, 1342513429. doi: $10.1073 /$ pnas. 230251897

Ries, G., Heller, W., Puchta, H., Sandermann, H., Seidlitz, H. K., and Hohn, B. (2000b). Elevated UV-B radiation reduces genome stability in plants. Nature 406, 98-101. doi: 10.1038/35017595

Roldán-Arjona, T., Garcia-Ortiz, M. V., and Ariza, R. R. (2002). DNA repair mechanisms of oxidative base damage induced by ionising radiation and ultraviolet light. Recent Res. Dev. Photochem. Photobiol. 6, 49-62.

Roth, N., Klimesch, J., Dukowic-Schulze, S., Pacher, M., Mannuss, A., and Puchta, H. (2012). The requirement for recombination factors differs considerably between different pathways of homologous double-strand break repair in somatic plant cells. Plant J. 72, 781-790. doi: 10.1111/j.1365313X.2012.05119.x

Roy, S. (2014). Maintenance of genome stability in plants: repairing DNA double strand breaks and chromatin structure stability. Front. Plant Sci. 5:487. doi: 10.3389/fpls.2014.00487

Rulten, S. L., Fisher, A. E. O., Robert, I., Zuma, M. C., Rouleau, M., Ju, L., et al. (2011). PARP-3 and APLF function together to accelerate nonhomologous end-Joining. Mol. Cell. 41, 33-45. doi: 10.1016/j.molcel.2010.1 2.006

Samach, A., Melamed-Bessudo, C., Avivi-Ragolski, N., Pietrokovski, S., and Levy, A. A. (2011). Identification of plant RAD52 homologs and characterization of the Arabidopsis thaliana RAD52-like genes. Plant Cell 23, 4266-4279. doi: 10.1105/tpc.111.091744

Santerre, A., and Britt, A. B. (1994). Cloning of a 3-methyladenine-DNA glycosylase from Arabidopsis thaliana. Proc. Natl. Acad. Sci. U.S.A. 91, 22402244. doi: 10.1073/pnas.91.6.2240

Sarasin, A., and Stary, A. (2007). New insights for understanding the transcription-coupled repair pathway. DNA Repair 6, 265-269. doi: 10.1016/j.dnarep.2006.12.001

Saurabh, S., Vidyarthi, A., and Prasad, D. (2014). RNA interference: concept to reality in crop improvement. Planta 239, 543-564. doi: 10.1007/s00425-0132019-5

Schärer, O. D. (2003). Chemistry and Biology of DNA Repair. Angew. Chem. Int. Ed. Engl. 42, 2946-2974. doi: 10.1002/anie.200200523

Schuermann, D., Molinier, J., Fritsch, O., and Hohn, B. (2005). The dual nature of homologous recombination in plants. Trends Genet. 21, 172-181. doi: 10.1016/j.tig.2005.01.002

Selby, C. P., and Sancar, A. (2006). A cryptochrome/photolyase class of enzymes with single-stranded DNA-specific photolyase activity. Proc. Natl. Acad. Sci. U.S.A. 103, 17696-17700. doi: 10.1073/pnas.0607993103

Shan, Q., Wang, Y., Chen, K., Liang, Z., Li, J., Zhang, Y., et al. (2013a). Rapid and efficient gene modification in rice and brachypodium using TALENs. Mol. Plant 6, 1365-1368. doi: $10.1093 / \mathrm{mp} / \mathrm{sss} 162$

Shan, Q., Wang, Y., Li, J., Zhang, Y., Chen, K., Liang, Z., et al. (2013b). Targeted genome modification of crop plants using a CRISPR-Cas system. Nat. Biotechnol. 31, 686-688. doi: 10.1038/nbt.2650
Sharma, P., Jha, A. B., Dubey, R. S., and Pessarakli, M. (2012). Reactive oxygen species, oxidative damage, and antioxidative defense mechanism in plants under stressful conditions. J. Bot. 2012:26. doi: 10.1155/2012/217037

Shikazono, N., Noguchi, M., Fujii, K., Urushibara, A., and Yokoya, A. (2009). The yield, processing, and biological consequences of clustered DNA damage induced by ionizing radiation. J. Radiat. Res. 50, 27-36. doi: 10.1269/jrr.08086

Shrivastav, N., Li, D., and Essigmann, J. M. (2010). Chemical biology of mutagenesis and DNA repair: cellular responses to DNA alkylation. Carcinogenesis 31, 59-70. doi: 10.1093/carcin/bgp262

Shukla, V. K., Doyon, Y., Miller, J. C., DeKelver, R. C., Moehle, E. A., Worden, S. E., et al. (2009). Precise genome modification in the crop species Zea mays using zinc-finger nucleases. Nature 459, 437-441. doi: 10.1038/nature07992

Shultz, R. W., Tatineni, V. M., Hanley-Bowdoin, L., and Thompson, W. F. (2007). Genome-wide analysis of the core DNA replication machinery in the higher plants Arabidopsis and rice. Plant Physiol. 144, 1697-1714. doi: 10.1104/pp.107.101105

Siaud, N., Dray, E., Gy, I., Gérard, E., Takvorian, N., and Doutriaux, M. P. (2004). Brca2 is involved in meiosis in Arabidopsis thaliana as suggested by its interaction with Dmcl. EMBO J. 23, 1392-1401. doi: 10.1038/sj.emboj. 7600146

Siebert, R., and Puchta, H. (2002). Efficient repair of genomic double-strand breaks by homologous recombination between directly repeated sequences in the Plant Genome. Plant Cell 14, 1121-1131. doi: 10.1105/tpc.001727

Singh, S. K., Roy, S., Choudhury, S. R., and Sengupta, D. N. (2010). DNA repair and recombination in higher plants: insights from comparative genomics of Arabidopsis and rice. BMC Genomics 11:443. doi: 10.1186/1471-216411-443

Smith, B. L., Bauer, G. B., and Povirk, L. F. (1994). DNA damage induced by bleomycin, neocarzinostatin, and melphalan in a precisely positioned nucleosome. Asymmetry in protection at the periphery of nucleosome-bound DNA. J. Biol. Chem. 269, 30587-30594.

Song, J., and Bent, A. F. (2014). Microbial pathogens trigger host dna double-strand breaks whose abundance is reduced by plant defense responses. PLoS Pathog 10:e1004030. doi: 10.1371/journal.ppat.1004030

Song, J., Durrant, W. E., Wang, S., Yan, S., Tan, E. H., and Dong, X. (2011). DNA repair proteins are directly involved in regulation of gene expression during plant immune response. Cell Host Microbe 9, 115-124. doi: 10.1016/j.chom.2011.01.011

Spampinato, C. P., Gomez, R. L., Galles, C., and Lario, L. D. (2009). From bacteria to plants: a compendium of mismatch repair assays. Mutat. Res. 682, 110-128. doi: 10.1016/j.mrrev.2009.07.001

Stapleton, A. E., Thornber, C. S., and Walbot, V. (1997). UV-B component of sunlight causes measurable damage in field-grown maize (Zea mays L.): developmental and cellular heterogeneity of damage and repair. Plant Cell Environ. 20, 279-290. doi: 10.1046/j.1365-3040.1997.d01-81.x

Stoilov, L. M., Mirkova, V. N., and Gecheff, K. I. (2000). HaeIII induces positiondependent chromosomal breakage in barley (Hordeum vulgare L.). Mutagenesis 15, 277-279. doi: 10.1093/mutage/15.3.277

Stolarek, M., Gruszka, D., Braszewska-Zalewska, A., and Maluszynski, M. (2015a). Alleles of newly identified barley gene HvPARP3 exhibit changes in efficiency of DNA repair. DNA Repair 28, 116-130. doi: 10.1016/j.dnarep.2015.02.018

Stolarek, M., Gruszka, D., Braszewska-Zalewska, A., and Maluszynski, M. (2015b). Functional analysis of the new barley gene HvKu80 indicates that it plays a key role in double-strand DNA break repair and telomere length regulation. Mutagenesis doi: 10.1093/mutage/gev033 [Epub ahead of print]

Strzalka, W., and Ziemienowicz, A. (2011). Proliferating cell nuclear antigen (PCNA): a key factor in DNA replication and cell cycle regulation. Ann. Bot. 107, 1127-1140. doi: 10.1093/aob/mcq243

Sugasawa, K. (2009). UV-DDB: a molecular machine linking DNA repair with ubiquitination. DNA Repair 8, 969-972. doi: 10.1016/j.dnarep.2009.05.001

Sutherland, B. M., Bennett, P. V., Sidorkina, O., and Laval, J. (2000). Clustered DNA damages induced in isolated DNA and in human cells by low doses of ionizing radiation. Proc. Natl. Acad. Sci. U.S.A. 97, 103-108. doi: 10.1073/pnas.97.1.103

Takahashi, M., Teranishi, M., Ishida, H., Kawasaki, J., Takeuchi, A., Yamaya, T., et al. (2011). Cyclobutane pyrimidine dimer (CPD) photolyase repairs ultraviolet-B-induced CPDs in rice chloroplast and mitochondrial DNA. Plant J. 66, 433-442. doi: 10.1111/j.1365-313X.2011.04500.x 
Takahashi, S., Nakajima, N., Saji, H., and Kondo, N. (2002). Diurnal change of cucumber CPD photolyase gene (CsPHR) expression and its physiological role in growth under UV-B Irradiation. Plant Cell Physiol. 43, 342-349. doi: $10.1093 / \mathrm{pcp} / \mathrm{pcf038}$

Takahashi, S., Teranishi, M., Izumi, M., Takahashi, M., Takahashi, F., and Hidema, J. (2014). Transport of rice cyclobutane pyrimidine dimer photolyase into mitochondria relies on a targeting sequence located in its C-terminal internal region. Plant J. 79, 951-963. doi: 10.1111/tpj.12598

Takashi, Y., Kobayashi, Y., Tanaka, K., and Tamura, K. (2009). Arabidopsis replication protein A 70a is required for DNA damage response and telomere length homeostasis. Plant Cell Physiol. 50, 1965-1976. doi: 10.1093/pcp/pcp140

Takeuchi, Y., Inoue, T., Takemura, K., Hada, M., Takahashi, S., Ioki, M., et al. (2007). Induction and inhibition of cyclobutane pyrimidine dimer photolyase in etiolated cucumber (Cucumis sativus) cotyledons after ultraviolet irradiation depends on wavelength. J. Plant Res. 120, 365-374. doi: 10.1007/s10265-0060065-9

Takeuchi, Y., Murakami, M., Nakajima, N., Kondo, N., and Nikaido, O. (1998). The photorepair and photoisomerization of DNA lesions in etiolated cucumber cotyledons after irradiation by UV-B depends on wavelength. Plant Cell Physiol. 39, 745-750. doi: 10.1093/oxfordjournals.pcp.a029429

Tam, S., Hays, J., and Chetelat, R. (2011). Effects of suppressing the DNA mismatch repair system on homeologous recombination in tomato. Theor. Appl. Genet. 123, 1445-1458. doi: 10.1007/s00122-011-1679-4

Tam, S., Samipak, S., Britt, A., and Chetelat, R. (2009). Characterization and comparative sequence analysis of the DNA mismatch repair MSH2 and MSH7 genes from tomato. Genetica 137, 341-354. doi: 10.1007/s10709-009-9 398-3

Tamura, K., Adachi, Y., Chiba, K., Oguchi, K., and Takahashi, H. (2002). Identification of Ku70 and Ku80 homologues in Arabidopsis thaliana: evidence for a role in the repair of DNA double-strand breaks. Plant J. 29, 771-781. doi: 10.1046/j.1365-313X.2002.01258.x

Tanaka, A., Shikazono, N., and Hase, Y. (2010). Studies on biological effects of ion beams on lethality, molecular nature of mutation, mutation rate, and spectrum of mutation phenotype for mutation breeding in higher plants. J. Radiat. Res. 51, 223-233. doi: 10.1269/jrr.09143

Taylor, R. M., Nikaido, O., Jordan, B. R., Rosamond, J., Bray, C. M., and Tobin, A. K. (1996). Ultraviolet-B-induced DNA lesions and their removal in wheat (Triticum aestivum L.) leaves. Plant Cell Environ. 19, 171-181. doi: 10.1111/j.1365-3040.1996.tb00238.x

Teranishi, M., Iwamatsu, Y., Hidema, J., and Kumagai, T. (2004). Ultraviolet-B sensitivities in japanese lowland rice cultivars: cyclobutane pyrimidine dimer photolyase activity and gene mutation. Plant Cell Physiol. 45, 1848-1856. doi: $10.1093 / \mathrm{pcp} / \mathrm{pch} 215$

Teranishi, M., Nakamura, K., Furukawa, H., and Hidema, J. (2013). Identification of a phosphorylation site in cyclobutane pyrimidine dimer photolyase of rice. Plant Physiol. Biochem. 63, 24-29. doi: 10.1016/j.plaphy.2012.11.003

Teranishi, M., Nakamura, K., Morioka, H., Yamamoto, K., and Hidema, J. (2008). The native cyclobutane pyrimidine dimer photolyase of rice is phosphorylated. Plant Physiol. 146, 1941-1951. doi: 10.1104/pp.107.110189

Thiagarajan, V., Byrdin, M., Eker, A. P. M., Müller, P., and Brettel, K. (2011). Kinetics of cyclobutane thymine dimer splitting by DNA photolyase directly monitored in the UV. Proc. Natl. Acad. Sci. U.S.A. 108, 9402-9407. doi: $10.1073 /$ pnas. 1101026108

Thoma, F. (2005). Repair of UV lesions in nucleosomes - intrinsic properties and remodeling. DNA Repair 4, 855-869. doi: 10.1016/j.dnarep.2005.04.005

Thompson, C. L., and Sancar, A. (2002). Photolyase/cryptochrome blue-light photoreceptors use photon energy to repair DNA and reset the circadian clock. Oncogene 21, 9043-9056. doi: 10.1038/sj.onc.1205958

Tilbrook, K., Arongaus, A. B., Binkert, M., Heijde, M., Yin, R., and Ulm, R. (2013). The UVR8 UV-B photoreceptor: perception, signaling and response. Arabidopsis Book 11, e0164. doi: 10.1199/tab.0164

Till, B. J., Reynolds, S. H., Greene, E. A., Codomo, C. A., Enns, L. C., Johnson, J. E., et al. (2003). Large-scale discovery of induced point mutations with high-throughput TILLING. Genome Res. 13, 524-530. doi: 10.1101/gr.977903

Tornaletti, S. (2005). Transcription arrest at DNA damage sites. Mutat. Res. 577, 131-145. doi: 10.1016/j.mrfmmm.2005.03.014

Tornaletti, S., Reines, D., and Hanawalt, P. C. (1999). Structural characterization of RNA polymerase II complexes arrested by a cyclobutane pyrimidine dimer in the transcribed strand of template DNA. J. Biol. Chem. 274, 24124-24130. doi: 10.1074/jbc.274.34.24124

Townsend, J. A., Wright, D. A., Winfrey, R. J., Fu, F., Maeder, M. L., Joung, J. K., et al. (2009). High-frequency modification of plant genes using engineered zinc-finger nucleases. Nature 459, 442-445. doi: 10.1038/nature 07845

Tuteja, N., Ahmad, P., Panda, B. B., and Tuteja, R. (2009). Genotoxic stress in plants: shedding light on DNA damage, repair and DNA repair helicases. Mutat. Res. 681, 134-149. doi: 10.1016/j.mrrev.2008.06.004

Uchiyama, Y., Kimura, S., Yamamoto, T., Ishibashi, T., and Sakaguchi, K. (2004). Plant DNA polymerase $\lambda$, a DNA repair enzyme that functions in plant meristematic and meiotic tissues. Eur. J. Biochem. 271, 2799-2807. doi: 10.1111/j.1432-1033.2004.04214.x

Uchiyama, Y., Takeuchi, R., Kodera, H., and Sakaguchi, K. (2009). Distribution and roles of X-family DNA polymerases in eukaryotes. Biochimie 91, 165-170. doi: 10.1016/j.biochi.2008.07.005

Ueda, T., and Nakamura, C. (2011). Ultraviolet-defense mechanisms in higher plants. Biotechnol. Biotechnol. Equip. 25, 2177-2182. doi: 10.5504/BBEQ.2011.0001

van Attikum, H., and Gasser, S. M. (2009). Crosstalk between histone modifications during the DNA damage response. Trends Cell Biol. 19, 207-217. doi: 10.1016/j.tcb.2009.03.001

van Harten, A. M. (1998). Mutation Breeding: Theory and Practical Applications. Cambridge: Cambridge University Press.

Van Marcke, I., and Angenon, G. (2013). Genomic stability in Nicotiana plants upon silencing of the mismatch repair gene MSH2. Plant Biotechnol. Rep. 7, 467-480. doi: 10.1007/s11816-013-0285-0

Vonarx, E. J., Tabone, E. K., Osmond, M. J., Anderson, H. J., and Kunz, B. A. (2006). Arabidopsis homologue of human transcription factor IIH/nucleotide excision repair factor $\mathrm{p} 44$ can function in transcription and DNA repair and interacts with AtXPD. Plant J. 46, 512-521. doi: 10.1111/j.1365-313X.2006. 02705.x

Voytas, D. F. (2013). Plant genome engineering with sequence-specific nucleases. Annu. Rev. Plant Biol. 64, 327-350. doi: 10.1146/annurev-arplant-042811105552

Walker, J. R., Corpina, R. A., and Goldberg, J. (2001). Structure of the Ku heterodimer bound to DNA and its implications for double-strand break repair. Nature 412, 607-614. doi: 10.1038/35088000

Watanabe, K., Yamada, N., and Takeuchi, Y. (2006). Oxidative DNA damage in cucumber cotyledons irradiated with ultraviolet light. J. Plant Res. 119, 239-246. doi: 10.1007/s10265-006-0266-2

Waterworth, W. M., Drury, G. E., Bray, C. M., and West, C. E. (2011). Repairing breaks in the plant genome: the importance of keeping it together. New Phytol. 192, 805-822. doi: 10.1111/j.1469-8137.2011.03926.x

Waterworth, W. M., Jiang, Q., West, C. E., Nikaido, M., and Bray, C. M. (2002). Characterization of Arabidopsis photolyase enzymes and analysis of their role in protection from ultraviolet-B radiation. J. Exp. Bot. 53, 1005-1015. doi: 10.1093/jexbot/53.371.1005

Waterworth, W. M., Kozak, J., Provost, C. M., Bray, C. M., Angelis, K. J., and West, C. E. (2009). DNA ligase 1 deficient plants display severe growth defects and delayed repair of both DNA single and double strand breaks. BMC Plant Biol. 9:79. doi: 10.1186/1471-2229-9-79

Wei, W., Ba, Z., Gao, M., Wu, Y., Ma, Y., and Amiard, S. (2012). A role for small RNAs in DNA double-strand break repair. Cell 149, 101-112. doi: 10.1016/j.cell.2012.03.002

Weinthal, D., Tovkach, A., Zeevi, V., and Tzfira, T. (2010). Genome editing in plant cells by zinc finger nucleases. Trends Plant Sci. 15, 308-321. doi: 10.1016/j.tplants.2010.03.001

Wendt, T., Holm, P., Starker, C., Christian, M., Voytas, D., Brinch-Pedersen, H., et al. (2013). TAL effector nucleases induce mutations at a pre-selected location in the genome of primary barley transformants. Plant Mol. Biol. 83, 279-285. doi: 10.1007/s11103-013-0078-4

West, C. E., Waterworth, W. M., Jiang, Q., and Bray, C. M. (2000). Arabidopsis DNA ligase IV is induced by $\gamma$-irradiation and interacts with an Arabidopsis homologue of the double strand break repair protein XRCC4. Plant J. 24, 67-78. doi: 10.1046/j.1365-313x.2000.00856.x

West, C. E., Waterworth, W. M., Story, G. W., Sunderland, P. A., Jiang, Q., and Bray, C. M. (2002). Disruption of the Arabidopsis AtKu80 gene demonstrates 
an essential role for AtKu80 protein in efficient repair of DNA double-strand breaks in vivo. Plant J. 31, 517-528. doi: 10.1046/j.1365-313X.2002.01370.x

Wu, Q., Christensen, L. A., Legerski, R. J., and Vasquez, K. M. (2005). Mismatch repair participates in error-free processing of DNA interstrand crosslinks in human cells. EMBO Rep. 6, 551-557. doi: 10.1038/sj.embor.7400418

Wu, S. Y., Culligan, K., Lamers, M., and Hays, J. (2003). Dissimilar mispair-recognition spectra of Arabidopsis DNA-mismatch-repair proteins MSH2•MSH6 (MutS $\alpha$ ) and MSH2•MSH7 (MutS $\gamma)$. Nucleic Acids Res. 31, 6027-6034. doi: 10.1093/nar/gkg780

Xiao, W., Yang, Q., Chen, Z., Wang, H., Guo, T., Liu, Y., et al. (2008). Blast-resistance inheritance of space-induced rice lines and their genomic polymorphism by microsatellite markers. Sci. Agric. Sin. 41, 3952-3958.

Xie, K., and Yang, Y. (2013). RNA-Guided genome editing in plants using a CRISPR-cas system. Mol. Plant 6, 1975-1983. doi: 10.1093/mp/sst119

Xu, J., Li, M., Chen, L., Wu, G., and Li, H. (2012a). Rapid generation of rice mutants via the dominant negative suppression of the mismatch repair protein OsPMS1. Theor. Appl. Genet. 125, 975-986. doi: 10.1007/s00122-012-1888-5

Xu, Y.-Z., Santamaria, R. D. L. R., Virdi, K. S., Arrieta-Montiel, M. P., Razvi, F., $\mathrm{Li}, \mathrm{S}$., et al. (2012b). The chloroplast triggers developmental reprogramming when MUTS HOMOLOG1 is suppressed in plants. Plant Physiol. 159, 710-720. doi: $10.1104 /$ pp.112.196055

Yamamoto, A., Tanbir, N., Hirouchi, T., Teranishi, M., Hidema, J., Morioka, H., et al. (2008). Temperature-sensitive photoreactivation of cyclobutane thymine dimer in soybean. J. Radiat. Res. 49, 189-196. doi: 10.1269/jrr.07091

Yang, Z., Tang, L., Li, M., Chen, L., Xu, J., Wu, G., et al. (2010). Monitoring homologous recombination in rice (Oryza sativa L.). Mutat. Res. 691, 55-63. doi: 10.1016/j.mrfmmm.2010.07.005

Yao, Y., Bilichak, A., Golubov, A., Blevins, T., and Kovalchuk, I. (2010). Differential sensitivity of Arabidopsis siRNA biogenesis mutants to genotoxic stress. Plant Cell Rep. 29, 1401-1410. doi: 10.1007/s00299-010-0930-9

Yi, C., and He, C. (2013). DNA repair by reversal of DNA damage. Cold Spring Harb. Perspect. Biol. 5:a012575. doi: 10.1101/cshperspect.a012575

Yoshihara, R., Imaki, T., Hori, M., Watanabe, C., Yamamoto, K., and Takimoto, K. (2005). CPD photolyase gene from Spinacia oleracea: repair of UV-damaged
DNA and expression in plant organs. J. Radiat. Res. 46, 157-164. doi: $10.1269 /$ jrr.46.157

Yoshihara, R., Nakane, C., Sato, R., Yasuda, A., and Takimoto, K. (2008). Silencing of CPD photolyase makes Arabidopsis hypersensitive and hypermutable in response to UV-B Radiation. Genes Environ. 30, 53-61. doi: 10.3123 /jemsge.30.53

Yoshiyama, K., Sakaguchi, K., and Kimura, S. (2013). DNA damage response in plants: conserved and variable response compared to animals. Biology 2, 1338-1356. doi: 10.3390/biology2041338

Yoshiyama, K. O., Kimura, S., Maki, H., Britt, A. B., and Umeda, M. (2014). The role of SOG1, a plant-specific transcriptional regulator, in the DNA damage response. Plant Signal. Behav. 9:e28889. doi: 10.4161/psb.28889

Zhang, C., Guo, H., Zhang, J., Guo, G., Schumaker, K. S., and Guo, Y. (2010a). Arabidopsis cockayne syndrome A-like proteins $1 \mathrm{~A}$ and $1 \mathrm{~B}$ form a complex with CULLIN4 and damage DNA binding protein $1 \mathrm{~A}$ and regulate the response to UV irradiation. Plant Cell 22, 2353-2369. doi: 10.1105/tpc.110.07 3973

Zhang, F., Maeder, M. L., Unger-Wallace, E., Hoshaw, J. P., Reyon, D., Christian, M., et al. (2010b). High frequency targeted mutagenesis in Arabidopsis thaliana using zinc finger nucleases. Proc. Natl. Acad. Sci. U.S.A. 107, 12028-12033. doi: 10.1073/pnas.0914991107

Zhou, X., Wang, G., and Zhang, W. (2007). UV-B responsive microRNA genes in Arabidopsis thaliana. Mol. Syst. Biol. 3, 103. doi: 10.1038/msb4100143

Conflict of Interest Statement: The authors declare that the research was conducted in the absence of any commercial or financial relationships that could be construed as a potential conflict of interest.

Copyright (C) 2015 Manova and Gruszka. This is an open-access article distributed under the terms of the Creative Commons Attribution License (CC BY). The use, distribution or reproduction in other forums is permitted, provided the original author(s) or licensor are credited and that the original publication in this journal is cited, in accordance with accepted academic practice. No use, distribution or reproduction is permitted which does not comply with these terms. 